\title{
Polypharmacology of carbonic anhydrase inhibitors
}

\author{
C. T. Supuran ${ }^{1}$, A. Mugelli ${ }^{2}$
}

${ }^{1}$ Università degli Studi di Firenze, NEUROFARBA Department, Sezione di Scienze Farmaceutiche. Via U. Schiff 6, I-50019 Sesto Fiorentino (Florence), Italy

E-mail: claudiu.supuran@unifi.it

${ }^{2}$ Università degli Studi di Firenze, NEUROFARBA Department, Sezione di Farmacologia, viale Pieraccini 6, 50100 Firenze, Italy

E-mail: alessandro.mugelli@unifi.it

\section{Summary}

Carbonic anhydrases (CAs, EC 4.2.1.1) are widespread metalloenzymes all over the phylogenetic tree, with 16 different isoforms present in mammals. CAs are efficient catalysts for the reversible hydration of carbon dioxide to bicarbonate and are inhibited by several classes of compounds such as the sulfonamides and their isosteres, sulfamates and sulfamides. A large number of clinically used drugs/agents in clinical development show significant inhibitory activity against the human (h) CA isoforms. Such compounds have applications as diuretics and antiglaucoma drugs, anticonvulsants, with some derivatives in clinical development as anticancer agents/diagnostic tools, or as antiobesity drugs. Several drugs originally discovered for other targets, such as such as the antiepileptics topiramate, zonisamide, and lacosamide; the sulfonamide coxibs (celecoxib, valdecoxib and paricoxib), or the protein kinase inhibitors pazopanib, imatinib and nilotinib, also show significant inhibition of many pharmacologically relevant CA isoforms. This polypharmacology of the CA inhibitors (CAIs) thus affords for novel applications for these drugs, such as for example the antiobesity action of topiramate and zonisamide (thought to be due to inhibition of two mitochondrial CA isoforms) or the antitumor activity of most sulfonamides and also coxibs and kinase inhibitors, which strongly inhibit the tumor-associated isoforms CA IX and XII. Novel applications of CAIs have also emerged in the treatment of rheumatoid arthritis, neuropathic pain and cerebral ischemia, considering the off-target activity/polypharmacology of well-known, clinically used drugs targeting these enzymes.

\section{Introduction}

The carbonic anhydrases (CAs, EC 4.2.1.1) are ubiquitous zinc enzymes, present in prokaryotes and eukaryotes, being encoded by seven distinct, evolutionarily unrelated gene families: the $\alpha$-CAs (present in vertebrates, Bacteria, algae and cytoplasm of green plants), the $\beta$-CAs (predominantly in Bacteria, some Archaea, algae, chloroplasts of both mono- as well as dicotyledons and some fungi), the $\gamma$-CAs (mainly in Archaea and some Bacteria), the $\delta$ - and $\xi$-CAs present in marine diatoms, the $\eta$-class discovered in protozoans and the $\Theta-C A s$ present in diatoms [1-9]. In mammals, 16 different $\alpha$-CA isozymes were described so far, with very different subcellular localization, catalytic activity 
and tissue distribution [1-8]. Basically, there are eight cytosolic forms (CA I-III, CA VII, CA XIII as well as the noncatalytic CA VIII, $\mathrm{X}$ and $\mathrm{XI}$ proteins), five membrane-bound/transmembrane isozymes with extracellular active site (CA IV, CA IX, CA XII, CA XIV and CA
$\mathrm{XV}$ ), two mitochondrial forms (CA VA and CA VB), as well as one secreted isozyme, CA VI (in saliva and milk) [1-12]. Table I shows the catalytic activity for the physiologic reaction as well as distribution and physiological role of these enzymes.

Table I. Kinetic parameters for $\mathrm{CO} 2$ hydration reaction catalysed by the 16 vertebrate $\alpha$-CA isozymes, at $20{ }^{\circ} \mathrm{C}$ and $\mathrm{pH} 7.5$, and their subcellular/tissue localization

\begin{tabular}{|c|c|c|c|c|c|c|}
\hline Isozyme & $\begin{array}{l}\mathbf{k}_{\mathrm{cat}} \\
\left(\mathrm{s}^{-1}\right)\end{array}$ & $\begin{array}{l}\mathbf{K}_{\mathbf{m}} \\
(\mathbf{m M})\end{array}$ & $\begin{array}{l}\mathbf{k}_{\text {cat }} / \mathbf{K}_{\mathbf{m}} \\
\left(\mathbf{M}^{-1} \cdot \mathbf{s}^{-1}\right)\end{array}$ & $\begin{array}{l}\text { Subcellular } \\
\text { localization }\end{array}$ & $\begin{array}{l}\text { Tissue/organ } \\
\text { localization }\end{array}$ & Ref. \\
\hline hCA I & $2.0 .10^{5}$ & 4.0 & $5.0 .10^{7}$ & cytosol & Erythrocytes, GI tract & $1-3$ \\
\hline hCA II & $1.4 .10^{6}$ & 9.3 & $1.5 .10^{8}$ & cytosol & $\begin{array}{l}\text { Erythrocytes, eye, GI tract } \\
\text { (ubiquitous), Bone osteoclasts, } \\
\text { kidney, lung, testis, brain }\end{array}$ & $1-3$ \\
\hline hCA III & $1.3 .10^{4}$ & 41.3 & $3.1 .10^{5}$ & cytosol & Skeletal muscle, adypocytes & $1-3$ \\
\hline hCA VI & $1.1 .10^{6}$ & 21.5 & $5.1 .10^{7}$ & membrane-bound & $\begin{array}{l}\text { Kidney , lung, pancreas, brain } \\
\text { capillaries, colon, heart muscle }\end{array}$ & $1-3,6$ \\
\hline hCA VA & $2.9 .10^{5}$ & 10.0 & $2.9 .10^{7}$ & mitochondria & liver & $1-3,7$ \\
\hline hCA VB & $9.5 \cdot 10^{5}$ & 9.7 & $9.8 .10^{7}$ & mitochondria & $\begin{array}{l}\text { heart and skeletal muscle, } \\
\text { pancreas, kidney, spinal cord, GI } \\
\text { tract }\end{array}$ & $1-3,7$ \\
\hline hCA VI & $3.4 .10^{5}$ & 6.9 & 4.9. $10^{7}$ & Secrete (saliva/milk) & salivary and mammary glands & 1,11 \\
\hline hCA VII & $9.5 .10^{5}$ & 11.4 & $8.3 \cdot 10^{7}$ & cytosol & CNS & 1,12 \\
\hline hCA VIII & - & - & - & cytosol & CNS & $1-3$ \\
\hline hCA IX & $1.1 .10^{6}$ & 7.5 & $1.5 .10^{8}$ & transmembrane & Tumors; GI mucosa & $\begin{array}{l}1- \\
5,15\end{array}$ \\
\hline hCA X & - & - & - & cytosol & CNS & $1-3$ \\
\hline hCA XI & - & - & - & cytosol & CNS & $1-3$ \\
\hline hCA XII & $4.2 .10^{5}$ & 12.0 & $3.5 .10^{7}$ & transmembrane & $\begin{array}{l}\text { Renal, intestinal, reproductive } \\
\text { epithelia }\end{array}$ & $1-4$ \\
\hline hCA XIII & $1.5 .10^{5}$ & 13.8 & $1.1 .10^{7}$ & cytosol & $\begin{array}{l}\text { kidney, brain, lung, gut, } \\
\text { reproductive tract }\end{array}$ & $1-3$ \\
\hline hCA XIV & $3.1 .10^{5}$ & 7.9 & $3.9 .10^{7}$ & transmembrane & kidney, brain, liver & $\begin{array}{l}1- \\
4,14\end{array}$ \\
\hline mCA XV & $4.7 .10^{5}$ & 14.2 & $3.3 .10^{7}$ & membrane-bound & kidney & 1,9 \\
\hline
\end{tabular}

$\mathrm{h}=$ human; $\mathrm{m}=$ mouse enzyme. $\mathrm{hCA}$ VIII, $\mathrm{X}$ and $\mathrm{XI}$ are devoid of catalytic activity 
These enzymes catalyze a very simple physiological reaction, the interconversion between carbon dioxide and the bicarbonate ion plus protons, and are involved in many crucial physiological processes in which these three simple chemical species are involved, such as respiration and transport of $\mathrm{CO}_{2} /$ bicarbonate between metabolizing tissues and lungs, $\mathrm{pH}$ and $\mathrm{CO}_{2}$ homeostasis, electrolyte secretion in a variety of tissues/organs, biosynthetic reactions (such as gluconeogenesis, lipogenesis and ureagenesis), bone resorption, calcification, tumorigenicity, and many other physiologic or pathologic processes [1-13].

In vertebrates, including Homo sapiens, the physiological functions of CAs have widely been investigated over the last 70 years (Table 27.1) [1-12]. Thus, isozymes CA I, II and IV are involved in respiration and regulation of the acid/base homeostasy [1]. These complex processes involve both the transport of $\mathrm{CO}_{2} /$ bicarbonate between metabolizing tissues and excretion sites (lungs, kidneys), facilitated $\mathrm{CO}_{2}$ elimination in capillaries and pulmonary microvasculature, elimination of $\mathrm{H}^{+}$ions in the renal tubules and collecting ducts, as well as reabsorption of bicarbonate in the brush border and thick ascending Henle loop in kidneys [1]. By producing the bicarbonate rich aqueous humor secretion (mediated by ciliary processes isozymes CA II, CA IV and CA XII) within the eye, CAs are involved in vision, and their misfunctioning leads to high intraocular pressure, and glaucoma [1]. CA II is also involved in the bone development and function, such as the differentiation of osteoclasts, or the provision of acid for bone resorption in osteoclasts [14]. CAs mediate the electrolytes secretion in many other tissues/organs, such as: CSF formation, by providing bicarbonate and regulating the $\mathrm{pH}$ in the choroid plexus; saliva production in acinar and ductal cells; gastric acid production in the stomach parietal cells; bile production, pancreatic juice production, intestinal ion transport [1-3]. CAs are also involved in gustation and olfaction, protection of gastrointestinal tract from extreme $\mathrm{pH}$ conditions, regulation of $\mathrm{pH}$ and bicarbonate concentration in the seminal fluid, muscle functions and adaptation to cellular stress [1-12]. Some isozymes, such as the mitochondrial CA VA/VB are involved in molecular signalling processes, such as insulin secretion signalling in pancreas $\beta$ cells. Isozymes CA II and VA/VB are involved in important metabolic processes, as they provide bicarbonate for ureagenesis, gluconeogenesis, fatty acids de novo biosynthesis and pyrimidine base synthesis [1-12]. Finally, some isozymes (such as CA IX, CA XII, CA VIII) are highly abundant in tumours, being involved in oncogenesis and tumor progression [1-5,15]. Although the physiological function of some isozymes (CA I, CA III, CA X, CA XI) is still unclear or poorly understood, from the data presented above one may understand the importance of CAs for a wide range of physiological processes, both in normal and pathological states. This may explain why inhibitors of these enzymes found a place in clinical medicine already in 1954, with acetazolamide (1) the first non-mercurial diuretic agent used clinically [1]. Inhibitors of these enzymes are used clinically as antiglaucoma agents, diuretics, antiepileptics, in the management of mountain sickness, gastric and duodenal ulcers, several minor neurological disorders, or for the management of osteoporosis among others [1-5,14]. Presently, research in the CA field for the drug design of pharmacological agents interacting with these enzymes is devoted on at least five fronts: (i) antiglaucoma drugs (targeting isozymes such as CA II, IV and XII) [1]; (ii) anticancer drugs/tumor diagnostic agents (targeting CA IX and CA XII, isozymes predominantly present in tumor cells) [1-3,15]; (iii) anticonvulsants (targeting CA II, VII, XII and XIV) [1,12]; (iv) antiobesity agents, which target the mitochondrial isoforms CA VA and CA VB [1,7]; and (v) mediators of neuropathic pain (targeting the brain cytosolic isoform CA VII) [16-19]. These multiple applications of the CA inhibitors (CAIs) are due several factors, among which the large number of isoforms in this family of enzymes, their different subcellular/tissue localization as well as their diverse physiological functions [1]. However, this is a doubleedged sword, since achieving selectivity for an inhibitor (drug) in a family with so many structurally related isozymes is rather difficult [1]. On the other hand, due to these factors, it is also not at all surprising that there are many examples of drugs originally designed to target other enzymes/proteins than the CAs, which were subsequently found to act as very potent CAIs and thus to possess unexpected (and sometimes valuable) 
applications, due to their interactions with some of these enzymes. In this article, we summarize some of the most important such examples, among which the widely used antiepileptics topiramate, zonisamide and lacosamide, the coxibs nonsteroidal anti-inflammatory agents celecoxib and valdecoxib, the steroid sulfatase inhibitors of the sulfamate type (in clinical development as antitumor agents), as well as the protein tyrosine kinase inhibitors imatinib and nilotinib.

\section{Carbonic anhydrase inhibition}

Several classes of CAIs are known: the metal complexing anions, the unsubstituted sulfonamides and their bioisosteres (sulfamates, sulfamides, etc), which bind to the $\mathrm{Zn}$ (II) ion of the enzyme either by substituting the non-protein zinc ligand or add to the metal coordination sphere, generating trigonalbipyramidal species [1-12]; the phenols [18,19], the polyamines [20], both of which anchor to the zinc-bound solvent molecule (water/hydroxide ion), and the coumarins [21,22] and fullerenes [23], which occlude the entrance to the active site, binding on the edge of the cavity. Sulfonamides/sulfamates/sulfamides bind in a tetrahedral geometry of the $\mathrm{Zn}$ (II) ion, in deprotonated state, with the nitrogen atom of the sulfonamide moiety coordinated to $\mathrm{Zn}$ (II) and an extended network of hydrogen bonds, involving residues Thr199 and Glu106, also participating to the anchoring of the inhibitor molecule to the metal ion [24].

The aromatic/heterocyclic part of the inhibitor (R) interacts with hydrophylic and hydrophobic residues of the cavity [24]. There are at least 30 clinically used drugs or agents in clinical development reported to possess significant CA inhibitory properties (compounds 1-25) [1]. Many other such derivatives belonging to the sulfonamide, sulfamate or sulfamide classes are constantly reported, being designed and synthesized by means of rational drug design processes [1].
Some of the clinically used compounds, such as acetazolamide $\mathbf{1}$, methazolamide $\mathbf{2}$, ethoxzolamide $\mathbf{3}$, sulthiame $\mathbf{4}$, and dichlorophenamide $\mathbf{5}$, are known for decades, and were initially developed in the search of novel diuretics or antiepileptics, in the 50s and 60s [1]. Although their use was not extensive as diuretics, it has been observed that such enzyme inhibitors may be employed for the systemic treatment of glaucoma [1]. Thus, many such drugs (e.g., acetazolamide, methazolamide and dichlorophenamide) are still presently used in ophthalmology, whereas two other derivatives, dorzolamide 6 and brinzolamide 7 have been developed in the $90 \mathrm{~s}$ as topically acting antiglaucoma agents [1]. It should be mentioned that among the various drugs/drug candidates of structure $\mathbf{1}$ 25, only the first seven compounds and the thiazide/high ceiling diuretics 19-25 have been originally developed as CAIs. All other compounds from this list are in fact good examples of polypharmacology, as they have been designed to act against other targets that have nothing to do with the CAs (Table II). As seen from data of Table 2, many of these drugs inhibit all CA isoforms significantly, in the nanomolar range [1].

The interaction of this class of CAIs with the enzyme is detailed in Fig. 1 where the binding of two clinically used sulfonamides (sulthiame $\mathbf{4}$ and zonisamide 10), one sulfamate (EMATE 13) and one sulfamide (the sulfamide analogues of topiramate 9) are shown schematically, as obtained by means of X-ray crystallography in adducts with the dominant human (h) isoform hCA II [25-32]. The sulfonamide, sulfamate and sulfamide zinc-binding groups (ZBGs) bind in a similar manner to the metal ion, whereas the remaining part of the organic scaffold participate in many types of polar and hydrophobic interactions which stabilize the enzyme-inhibitor adduct. As seen from data of Table II, many of these compounds are low nanomolar inhibitors against many $\mathrm{CA}$ isozymes. 
Table 2. Inhibition data with some of the clinically used sulfonamides/sulfamates 1-25 against isozymes I - XIV (the isoforms CA VIII, X and XI are devoid of catalytic activity and probably do not bind sulfonamides as they do not contain $\mathrm{Zn}$ (II) ions) [1].

\begin{tabular}{|c|c|c|c|c|c|c|c|c|c|c|c|c|c|c|}
\hline \multicolumn{7}{|c|}{ Isozyme* } & \multicolumn{8}{|c|}{$K_{I}(n M)$} \\
\hline & 1 & 2 & 3 & 4 & 5 & 6 & 7 & 8 & 9 & 10 & 11 & 12 & 13 & 14 \\
\hline hCA I ${ }^{a}$ & 250 & 50 & 25 & 374 & 1200 & $\begin{array}{l}5000 \\
0\end{array}$ & $\begin{array}{l}4500 \\
0\end{array}$ & 31 & 250 & 56 & 12000 & 3450 & 37 & 50000 \\
\hline 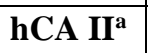 & 12 & 14 & 8 & 9 & 38 & 9 & 3 & 15 & 10 & 35 & 40 & 21 & 10 & 21 \\
\hline $\begin{array}{l}\text { hCA } \\
\text { III' }^{\mathbf{a}}\end{array}$ & $\begin{array}{l}2.1 \\
0^{5}\end{array}$ & $\begin{array}{l}7.1 \\
0^{5}\end{array}$ & $110^{6}$ & $\begin{array}{l}6.3 .1 \\
0^{5}\end{array}$ & $\begin{array}{l}6.8 . \\
10^{5}\end{array}$ & $\begin{array}{l}7.7 .1 \\
0^{5}\end{array}$ & $\begin{array}{l}1.1 .1 \\
0^{5}\end{array}$ & $\begin{array}{l}1040 \\
0\end{array}$ & $\begin{array}{l}7.8 . \\
10^{5}\end{array}$ & $\begin{array}{l}2.2 \\
10^{6}\end{array}$ & 10600 & $\begin{array}{l}7.0 \\
10^{4}\end{array}$ & $6.510^{5}$ & 7.4. $10^{4}$ \\
\hline $\begin{array}{l}\text { hCA } \\
\text { IV }^{\mathbf{a}}\end{array}$ & 74 & $\begin{array}{l}620 \\
0\end{array}$ & 93 & 95 & 15000 & 8500 & 3950 & 65 & 4900 & 8590 & 6.5 & 25 & nt & 880 \\
\hline $\begin{array}{l}\text { hCA } \\
\text { VA }^{\mathbf{a}}\end{array}$ & 63 & 65 & 25 & 81 & 630 & 42 & 50 & 79 & 63 & 20 & 174 & 765 & nt & 794 \\
\hline $\begin{array}{l}\text { hCA } \\
\text { VB }^{\mathbf{a}}\end{array}$ & 54 & 62 & 19 & 91 & 21 & 33 & $3^{\prime}$ & 23 & 30 & 6033 & 18 & 720 & nt & 93 \\
\hline $\begin{array}{l}\mathrm{hCA} \\
\mathrm{VI}^{\mathrm{a}}\end{array}$ & 11 & 10 & 43 & 134 & 79 & 10 & 0.9 & 47 & 45 & 89 & 0.8 & 653 & $\mathrm{nt}$ & 94 \\
\hline $\begin{array}{l}\text { hCA } \\
\text { VIII }^{\text {a }}\end{array}$ & 2.5 & 2.1 & 0.8 & 6 & 26 & 3.5 & 2.8 & 122 & 0.9 & 117 & 3630 & 23 & nt & 2170 \\
\hline $\begin{array}{l}\text { hCA } \\
\text { IX }^{\mathbf{a}}\end{array}$ & 25 & 27 & 34 & 43 & 50 & 52 & 37 & 24 & 58 & 5.1 & 46 & 34 & 30 & 16 \\
\hline $\begin{array}{l}\text { hCA } \\
\text { XIII }^{\text {b }}\end{array}$ & 5.7 & 3.4 & 22 & 56 & 50 & 3.5 & 3.0 & 3.4 & 3.8 & 11000 & 3.9 & 12 & 7.5 & 18 \\
\hline $\begin{array}{l}\text { mCA } \\
\text { XIII }^{a}\end{array}$ & 17 & 19 & 50 & 1450 & 23 & 18 & 10 & 11 & 47 & 430 & 295 & 1050 & $\mathrm{nt}$ & 98 \\
\hline $\begin{array}{l}\text { hCA } \\
\text { XIV }^{\text {a }}\end{array}$ & 41 & 43 & 25 & 1540 & 345 & 27 & 24 & 106 & 1460 & 5250 & 110 & 755 & $\mathrm{nt}$ & 689 \\
\hline $\begin{array}{l}\text { mCA } \\
X^{\text {a }}\end{array}$ & 72 & 65 & 58 & 65 & 95 & 61 & 61 & 72 & 78 & 634 & 73 & $\mathrm{nt}$ & $\mathrm{nt}$ & 45 \\
\hline
\end{tabular}

${ }^{*} \mathrm{~h}=$ human; $\mathrm{m}=$ murine isozyme.; $\mathrm{nt}=$ not tested, data not available. ${ }^{\mathrm{a}}$ Full length enzyme; ${ }^{\mathrm{b}}$ Catalytic domain. 
Table 2. (continued)

\begin{tabular}{|c|c|c|c|c|c|c|c|c|c|c|c|}
\hline \multicolumn{5}{|c|}{ Isozyme* } & \multicolumn{7}{|c|}{$\mathbf{K}_{\mathrm{I}}(\mathbf{n M})$} \\
\hline & 15 & 16 & 17 & 18 & 19a & 20 & 21 & 22 & 23 & 24 & 25 \\
\hline hCA I ${ }^{a}$ & 54000 & 50 & 2300 & 4000 & 328 & 35000 & 54000 & 348 & 51900 & 62 & 12400 \\
\hline $\begin{array}{l}\text { hCA } \\
\text { II }^{\mathbf{a}}\end{array}$ & 43 & 5950 & 45 & 21 & 290 & 1260 & 2000 & 138 & 2520 & 65 & 3050 \\
\hline $\begin{array}{l}\text { hCA } \\
\text { III }^{\mathbf{a}}\end{array}$ & 7.8 .104 & $1.0 .10^{5}$ & $1.310^{6}$ & $3.1 .10^{5}$ & $7.9 .10^{5}$ & nt & $6.1 .10^{5}$ & $1.1 .10^{4}$ & $2.3 .10^{5}$ & $3.2 .10^{6}$ & nt \\
\hline $\begin{array}{l}\text { hCA } \\
\text { IV }^{\mathbf{a}}\end{array}$ & 1340 & 7920 & 650 & 60 & 427 & nt & 216 & 196 & 213 & 564 & $\mathrm{nt}$ \\
\hline $\begin{array}{l}\text { hCA } \\
\text { VA }^{\mathbf{a}}\end{array}$ & 912 & 10060 & 134 & 88 & 4225 & nt & 750 & 917 & 890 & 499 & $\mathrm{nt}$ \\
\hline $\begin{array}{l}\text { hCA } \\
\text { VB }^{\mathbf{a}}\end{array}$ & 88 & 7210 & 76 & 70 & 603 & $\mathrm{nt}$ & 312 & 9 & 274 & 322 & $\mathrm{nt}$ \\
\hline $\begin{array}{l}\text { hCA } \\
\text { VI }^{\mathbf{a}}\end{array}$ & 572 & 935 & 145 & 65 & 3655 & nt & 1714 & 1347 & 1606 & 245 & $\mathrm{nt}$ \\
\hline $\begin{array}{l}\text { hCA } \\
\text { VII }^{\mathrm{a}}\end{array}$ & 3900 & 10 & 18 & 15 & 5010 & nt & 2.1 & 2.8 & 0.23 & 513 & $\mathrm{nt}$ \\
\hline $\begin{array}{l}\text { hCA } \\
\text { IX }^{\mathbf{a}}\end{array}$ & 27 & 103 & 24 & 14 & 367 & nt & 320 & 23 & 36 & 420 & $\mathrm{nt}$ \\
\hline $\begin{array}{l}\text { hCA } \\
\text { XII }\end{array}$ & 13 & 633 & 5 & 7 & 355 & nt & 5.4 & 4.5 & 10 & 261 & $\mathrm{nt}$ \\
\hline $\begin{array}{l}\text { mCA } \\
\text { XIII }^{a}\end{array}$ & 425 & 12100 & 76 & 21 & 3885 & nt & 15 & 15 & 13 & 550 & $\mathrm{nt}$ \\
\hline $\begin{array}{l}\text { hCA } \\
\text { XIV }^{\text {a }}\end{array}$ & 107 & 773 & 33 & 13 & 4105 & $\mathrm{nt}$ & 5432 & 4130 & 4950 & 52 & $\mathrm{nt}$ \\
\hline $\begin{array}{l}\text { mCA } \\
\mathbf{X V}^{\mathbf{a}}\end{array}$ & 66 & nt & $\mathrm{Nt}$ & $\mathrm{Nt}$ & $\mathrm{nt}$ & nt & $\mathrm{nt}$ & nt & $\mathrm{nt}$ & $\mathrm{nt}$ & $\mathrm{nt}$ \\
\hline
\end{tabular}

${ }^{*} \mathrm{~h}=$ human; $\mathrm{m}=$ murine isozyme.; $\mathrm{nt}=$ not tested, data not available. ${ }^{\mathrm{a}}$ Full length enzyme; ${ }^{\mathrm{b}}$ Catalytic domain. 

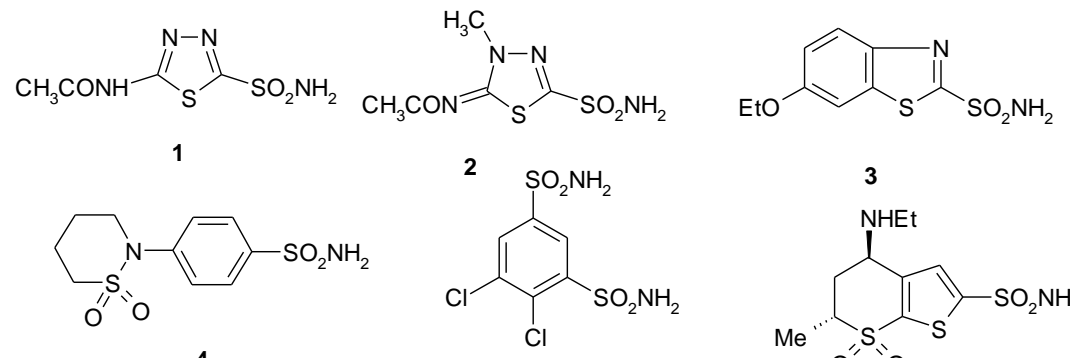<smiles>CCNC1CN(NCOC)S(=O)(=O)c2sc(S(N)(=O)=O)cc21</smiles><smiles>[R]S(=O)(=O)O</smiles>

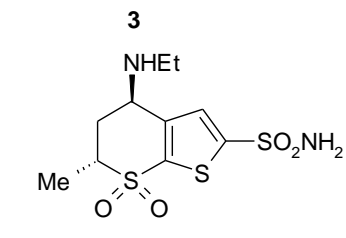

5<smiles>COc1cc(Cl)c(Cl)c(OS(N)(=O)=O)c1</smiles><smiles>NS(=O)(=O)c1ccc(S(=O)(=O)Nc2cccc3c(Cl)c[nH]c23)cc1</smiles>

8<smiles>CC1(C)OCC2OCC3OC(C)(C)OC3C2O1</smiles><smiles>N[R](N)(=O)Cc1noc2ccccc12</smiles>
10<smiles>CCN1CCCC1CNC(=O)c1cc(S(N)(=O)=O)ccc1OC</smiles>

11<smiles>NS(=O)(=O)Oc1ccc2c(c1)OC(=O)C1CCCCC21</smiles><smiles>CC12CCC3c4ccc(OS(N)(=O)=O)cc4CCC3C1CCC2=O</smiles>

12<smiles>Cc1onc(-c2ccccc2)c1-c1ccc(S(N)(=O)=O)cc1</smiles>

13<smiles>Cc1ccc(-c2cc(C(F)(F)F)nn2-c2ccc(S(N)(=O)=O)cc2)cc1</smiles>

15<smiles>O=C1NS(=O)(=O)c2ccccc21</smiles>

16<smiles>NS(=O)(=O)c1ccc(CCNC(=S)Nc2ccc(-c3c4ccc(=O)cc-4oc4cc(O)ccc34)c(C(=O)O)c2)cc1</smiles><smiles>Cc1cc(C)[n+](CCc2ccc(S(N)(=O)=O)cc2)c(C)c1</smiles>

18 
<smiles>[R6]c1cc2c(cc1S(N)(=O)=O)S(=O)(=O)N([R2])C([R3])N2</smiles>

19<smiles>CCC1NC(=O)c2cc(S(N)(=O)=O)c(Cl)cc2N1</smiles>

20<smiles>NS(=O)(=O)c1cc(C2(O)NC(=O)c3ccccc32)ccc1Cl</smiles>

22<smiles>NS(=O)(=O)c1cc(C(=O)O)c(NCc2ccco2)cc1Cl</smiles>

24 a: $\mathrm{R} 2=\mathrm{R} 3=\mathrm{H}, \mathrm{R} 6=\mathrm{Cl}$, Hydrochlorothiazide

b: $\mathrm{R} 2=\mathrm{R} 3=\mathrm{H}, \mathrm{R} 6=\mathrm{CF}_{3}$, Hydroflumethiazide

c: $\mathrm{R} 2=\mathrm{H}, \mathrm{R} 3=\mathrm{PhCH}_{2}, \mathrm{R} 6=\mathrm{CF}_{3}$, Bendroflumethiazide

d: $\mathrm{R} 2=\mathrm{H}, \mathrm{R} 3=\mathrm{CHCl}_{2}, \mathrm{R} 6=\mathrm{Cl}$, Trichloromethiazide

e: R2=Me, R3 $=\mathrm{CH}_{2} \mathrm{SCH}_{2} \mathrm{CF}_{3}, \mathrm{R} 6=\mathrm{Cl}$, Polythiazide

21<smiles>CC1Cc2ccccc2N1NC(=O)c1ccc(Cl)c(S(N)(=O)=O)c1</smiles>

23<smiles>CCCCNc1cc(C(=O)O)cc(S(N)(=O)=O)c1Oc1ccccc1</smiles>

25 
Figure 1. Schematic representation of the binding of the anticonvulsant sulfonamides sulthiame 4 (A) and zonisamide 10 (C) in complex with hCA II. Binding of the sulfamate CA inhibitor EMATE 13 to hCA II (B) and of the sulfamide analog of topiramate $\mathbf{9}$, to the hCA II active site are also shown, as obtained by means of X-ray crystallography (figures represent distances in $\AA$ ) [25-30]

A

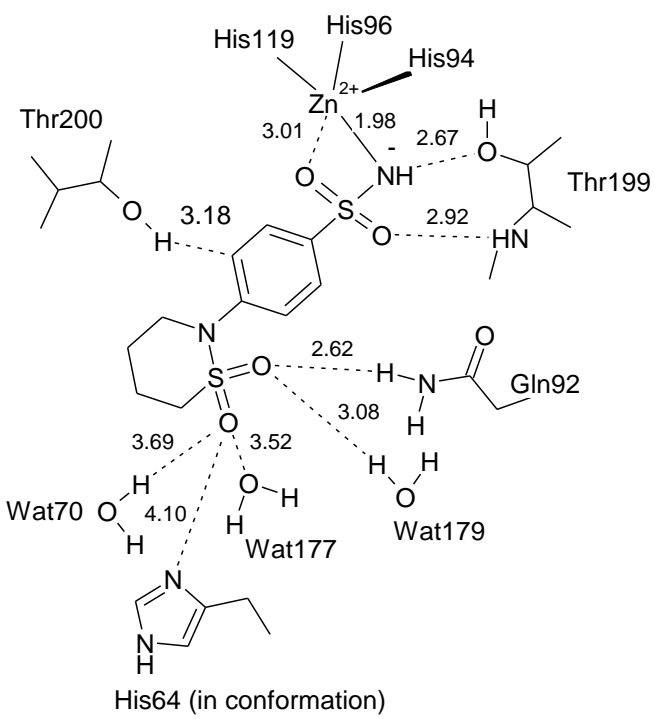

C

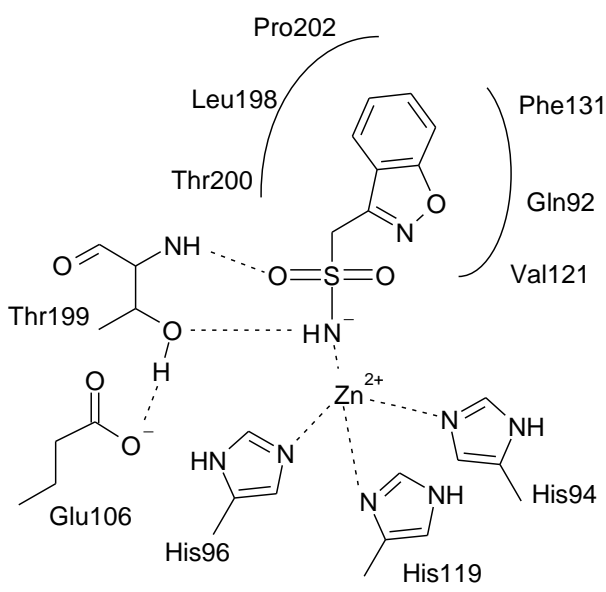

B

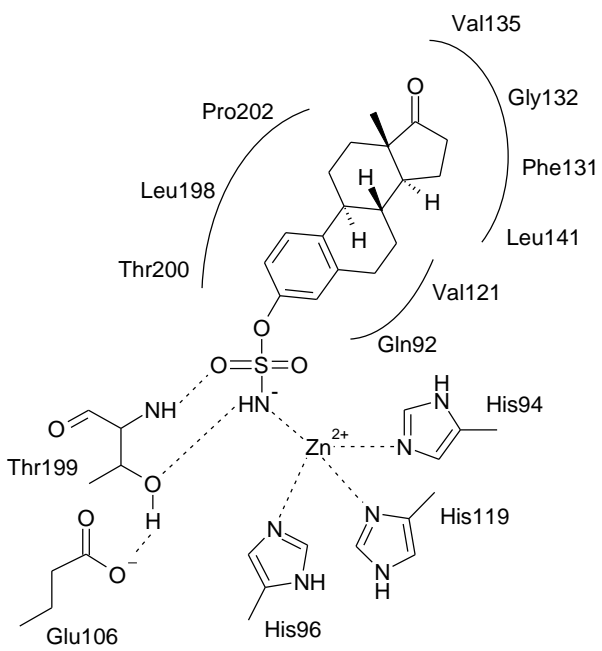

D

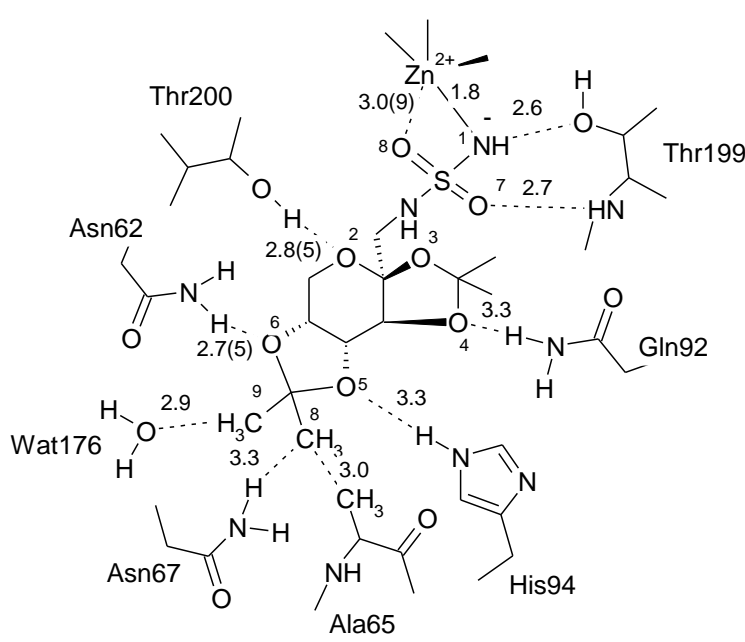


Anion inhibitors bind either in tetrahedral geometry of the metal ion or as trigonal-bipyramidal adducts, whereas the binding of coumarins, fullerenes and phenols/polyamines is a more complex process recently investigated in detail by means of kinetic and crystallographic studies [18-22]. These CAIs are not considered in detail here as they do not have clinical applications so far. Here we will discuss several interesting aspects of polypharmacology of several CAIs in clinical use.

\section{Topiramate and zonisamide: antiepileptics with potent antiobesity action}

Topiramate 9, a sugar sulfamate, is a clinically used antiepileptic drug discovered by Maryanoff's group in the 80 s by using an empirical approach, the maximal electroshock seizure (MES) test [33]. Topiramate is orally active and efficacious in various forms of epilepsy, refractory to other medication, has a rapid absorption, high bioavailability and long duration of action [33-37]. An interesting feature of this drug is that it has no structural relatedness to any other antiepileptic used clinically (such as the phenytoins, carbamazepines, barbiturates, benzodiazepines or GABA-scaffold derived antiepileptics). It is somehow related to zonisamide.

10 (1,2-benzoxazol-3-yl-methanesulfonamide), as both drugs contain a ZBG known to coordinate to the $\mathrm{Zn}(\mathrm{II})$ ion of CAs, the sulfonamide one in the case of zonisamide, and the sulfamate one in the case of topiramate [26,29-32]. The mechanism of action of this drug is not fully understood yet [35-37]. Several mechanisms of action were proposed so far [37] such as the enhancement of GABA-ergic transmission [37-40], the antagonism of kainate/AMPA receptors [40-43] and the inhibition of action potentials creation in neurons via antagonizing the activation of $\mathrm{Na}^{+}$channels [44-46]. Another mechanism of action of topiramate that has not been viewed as critical up to now, but that will be considered here in detail, is the inhibition of different
CA isozymes [29-32,47]. It is thought that the anticonvulsant effects of topiramate 9 or related sulfonamides (such as zonisamide 10) may be due to $\mathrm{CO}_{2}$ retention secondary to inhibition of the red blood cell and brain enzymes [47]. However, initially topiramate was classified as a very weak (millimolar) CA inhibitor by its discoverers [33], but it seems that rather unpurified enzymes have been used for assays. More recently the same group reported different results [48], showing that topiramate is a much stronger CA inhibitor (i.e., in the micromolar range) in a different assay set-up, using enzymes from different sources. Nevertheless, even in the latter report the efficacy against a series of CA isozymes was 10 times lower compared to acetazolamide, the sulfonamide CAI mostly used. This was in contradiction to data of Supuran's laboratory that clearly showed topiramate to be a very potent CA inhibitor [29-32]. These findings match with many clinically observed side effects of topiramate [49-53], which are in agreement with the typical pharmacological profiles of strong sulfonamide CAIs used as systemic antiglaucoma agents (acetazolamide 1, methazolamide 2, dichlorophenamide 5 [1]) and include paresthesias, nephrolithiasis, and weight loss, among others [1]. For the complete inhibition profile of topiramate $\mathbf{9}$ against all mammalian CA isozymes see data of Table 2 . These data show that topiramate inhibits eight $\mathrm{CA}$ isoforms with inhibition constants $<65 \mathrm{nM}$, hCA I with an inhibition constant of $250 \mathrm{nM}$ whereas three other isozymes are less inhibited $\left(\mathrm{K}_{\mathrm{IS}}\right.$ in the range of $1460 \mathrm{nM}-0.78 \mathrm{mM}$ ). What is however more significant is that many isozymes involved in crucial physiologic functions, such as CA II, CA IV, CA VA, CA VII, CA IX and CA XII are highly inhibited by this drug, sometimes (e.g., CA VII) in the subnanomolar range. A confirmation of the potent inhibition observed in solution has been obtained by the report of the X-ray crystal structure of topiramate in complex with two CA isoforms, hCA II $[29,30]$ and hCA I [31] (Figure 2). 
Figure 2. Schematic representations for the binding of topiramate 9 to hCA I (A), hCA II (B) and hCA VA (C) active site. Figures A and B were obtained by X-ray crystallography [29-31] whereas C by homology modelling [33].
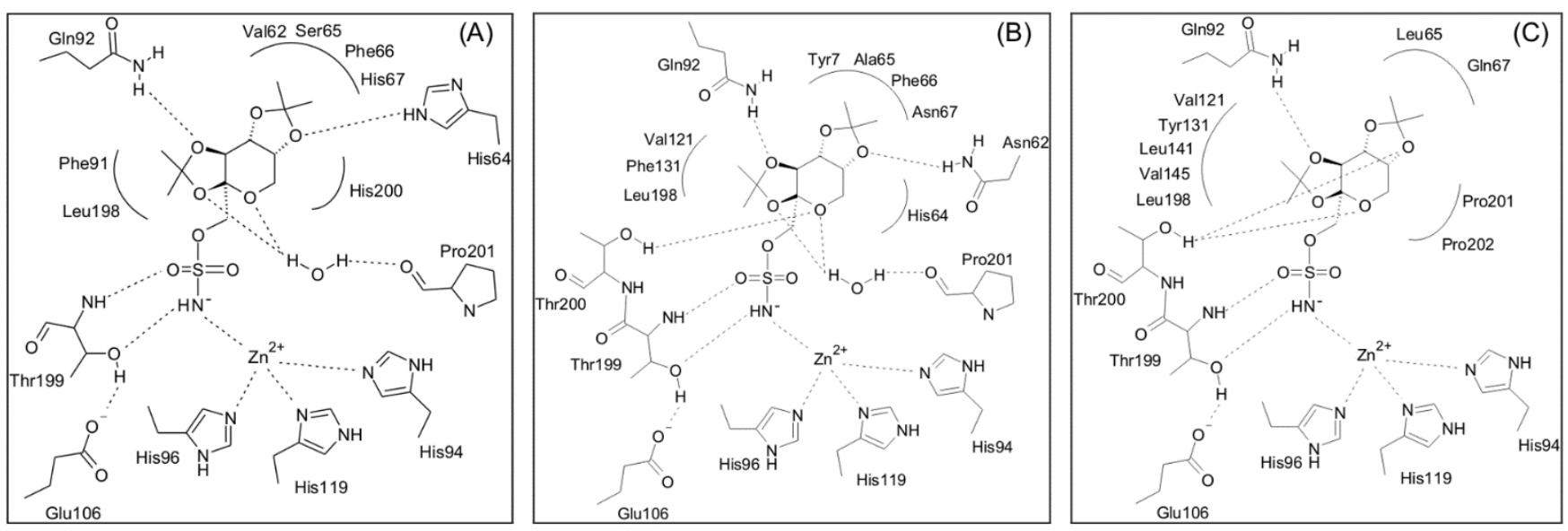

The deprotonated sulfamate moiety of topiramate is anchored to the $\mathrm{Zn}(\mathrm{II})$ ion similarly to the same moiety of EMATE shown in Fig. 1B. In addition, the organic scaffold of the inhibitor participates in six hydrogen bonds with amino acid residues and water molecules in the hCA II active site [29], and in five such interactions in the case of the hCA I adduct [31]. However, for the last isoform, a massive reorganization of the active site has been observed, a unique case in CA - inhibitor adducts [24,31]. A large number of hydrophobic interactions also stabilize further the topiramate adduct with both isoforms. In the figure is also presented the homology modeling for the binding of topiramate to hCA VA (Fig. 2C). Also in the case of this isoform, there are many polar and hydrophobic interaction between the inhibitor and various amino acid residues from the enzyme active site [32].

Zonisamide, 10

(1,2-benzisoxazole-3 methanesulfonamide), is a widely used antiepileptic drug [46,54,55]. In vitro studies with cultured neurons showed that zonisamide blocks repetitive firing of voltage-sensitive sodium channels and reduces voltagesensitive T-type calcium currents without affecting Ltype calcium currents $[46,54,55]$. Such a complicated mechanism of action may explain its efficacy in patients resistant to other antiepileptic drugs, whereas its pharmacokinetic profile is favorable for clinical use since the drug is rapidly and completely absorbed and has a long half-life (63-69h), which allows twice- or once-daily dosing $[46,54,55]$. Being an unsubstituted sulfonamide, zonisamide has also been investigated for the inhibition of CA by its discoverers [56,57], being concluded that although it binds significantly to erythrocytes [58] (where two CA isozymes, CA I and II are highly abundant) its CA inhibitory properties are rather weak, and thus, this phenomenon does not play any role in the anticonvulsant activity of the drug [5658]. However subsequent studies from this group [26] showed zonisamide to be a potent CAI for many isoforms such as CA I, II, VA, VI, VII, and IX (which are inhibited with $\mathrm{K}_{\mathrm{I}}<120 \mathrm{nM}$ ) [1,26,59]. The X-ray crystal structure of the hCA II - zonisamide complex has been also reported [26], its binding to the enzyme being schematically shown in Fig. 1C. The X-ray crystal data (at a resolution of $1.70 \AA$ ), showed that the sulfonamide moiety to participate in the classical interactions with the $\mathrm{Zn}$ (II) ion and the residues Thr199 and Glu106, whereas the benzisoxazole ring was found situated in the hydrophobic half of the active site, establishing a large number of strong van der Waals interactions $(<4.5 \AA)$ with residues Gln92, Val121, Phe131, Leu198, Thr200, Pro202 [26]. Thus, although topiramate 9 and zonisamide 10 possess so different chemical structures, and they bind diversely to the CA active sites, they have in common the property of behaving as very potent 
inhibitors of some CA isoforms involved in a crucial physiologic process, among which the de novo lipogenesis $[1,7,60]$.

The enzymes involved in this biochemical pathway are: the mitochondrial pyruvate carboxylase (PC), which is needed for the efflux of acetyl groups from the mitochondria to the cytosol where fatty-acid biosynthesis takes place $[1,60]$. Pyruvate is thereafter carboxylated to oxaloacetate in the presence of bicarbonate under the catalytic influence of the mitochondrial isozymes (CA VA and/or CA VB) $[1,60]$. The mitochondrial membrane is impermeable to acetylCoA, which reacts with oxaloacetate, leading to the formation of citrate, which is then translocated to the cytoplasm by means of the tricarboxylic acid transporter. As oxaloacetate is unable to cross the mitochondrial membrane, its decarboxylation regenerates pyruvate, which can then be transported into the mitochondria by means of the pyruvate transporter. The acetyl-CoA thus generated in the cytosol is in fact used for de novo lipogenesis, by carboxylation in the presence of acetylCoA carboxylase (ACC) and bicarbonate, with formation of malonyl-CoA, the conversion between $\mathrm{CO}_{2}$ and bicarbonate being assisted by CA II $[1,60]$. Subsequent steps involving the sequential transfer of acetyl groups lead to longer-chain fatty acids. For the reasons mentioned above, $\mathrm{CA}$ isozymes are critical to the entire process of fatty acid biosynthesis: CA VA and VB within the mitochondria (to provide enough substrate to PC), and CA II within the cytosol (for providing sufficient substrate to ACC) $[1,7,60]$. Furthermore, it has been demonstrated that inhibiting these enzymes with sulfonamide/sulfamate CAIs, leads to a profound decrease of lipogenesis $[1,7,60]$. Indeed, there are many reports regarding the side-effects observed in obese epileptic patients treated with topiramate $\mathbf{9}$ or zonisamide 10, leading to a significant weight loss [61-64]. The same effects have been observed in experimental animals [65] and topiramate has been approved as an antiobesity agent in 2012 [66]. Thus, side effects due to off-target inhibition of CAs (as both drugs have been claimed by their discoverers to be either weak CAIs - topiramate -or not CAIs at all zonisamide) may lead in fact to totally new applications of the two compounds. As there is a stringent need of effective antiobesity agents [7] with a novel mechanism of action (as the de novo lipogenesis inhibition is) the two compounds may also represent valuable leads for developing even more selective (or effective) CAIs targeting the mitochondrial $\mathrm{CA}$ isoforms involved in lipogenesis [1].

\section{Nonsteroidal anti-inflammatory agents: sulfonamide coxibs with antitumor activity due to CA IX/XII inhibition}

Cyclooxygenases (COXs) catalyze the committed step in the conversion of arachidonic acid to prostaglandins (PGs) and thromboxane, with at least three distinct isozymes, COX-1 - COX-3 isolated up to now [67-69]. The inducible COX-2 was shown to be associated with inflammatory conditions, whereas the constitutive form (COX-1) is responsible for the beneficial effects of the PGs $[67,68]$. The development and the use of these specific inhibitors, collectively called coxibs, were immediately considered as a real breakthrough in antiinflammatory therapy [67]. Thus, the development of the "coxibs", was based on the hypothesis that this isoform mediates inflammation in several organs via the biosynthesis of prostaglandins $\mathrm{E}_{2}$ and $\mathrm{I}_{2}$ (or prostacyclin) and that COX-1 was the source of the same prostaglandins in the gastric epithelium, where they would act as cytoprotective mediators. The sulfonamide celecoxib 14 (Celebrex $\left.{ }^{\circledR}\right)$ and the methylsulfone rofecoxib (Vioxx $\left.{ }^{\circledR}\right)$ were the first two coxibs approved by the FDA and launched in 1999 by Pfizer and Merck \& Co., respectively [67]. A second generation of coxibs emerged later onto the market. The sulfonamide valdecoxib 15 (Bextra ${ }^{\circledR}$, Pfizer-Pharmacia) was then approved by the FDA and launched in 2002, but this compound is no longer in clinical use after the withdrawal of Vioxx from the market in 2004, due to the cardiovascular side effects of the drug.

Our group showed that celecoxib $\mathbf{1 4}$ and valdecoxib 15, which contain primary sulfamoyl moieties in their molecules, but not the methylsulfone analogues (of the rofecoxib type) act as potent inhibitors of several CA isozymes, with affinity for some of them of the same order of magnitude as those of clinically used CAIs, in the low nanomolar range [70,71]. For example, isoforms 
CA II, VB, IX and XII are inhibited with $\mathrm{K}_{\mathrm{IS}}<100 \mathrm{nM}$ by the two drugs, but CA II, IX and XII shows in fact inhibition in the low nanomolar range $\left(\mathrm{K}_{\mathrm{I}} \mathrm{S}<40 \mathrm{nM}\right)$ $[1,70,71]$. Furthermore, the X-ray crystal structure of the adducts of the two drugs bound to the physiologically dominant isoform hCA II have also been reported [70,71] (Figure 3).

Figure 3. Binding of celecoxib 14 (sky blue) and valdecoxib 15 (magenta) to hCA II as observed in the X-ray crystallographic adducts of the two drugs [70,71]. The $\mathrm{Zn}$ (II) ion, its three His ligands and amino acid residues from the enzyme active site involved in the binding of the two drugs are also shown. Although celecoxib and valdecoxib possess a very similar shape of the molecule, their orientation within the hCA II active site are very different, except for the benzenesulfonamide fragment of the two molecules which are superimposable.

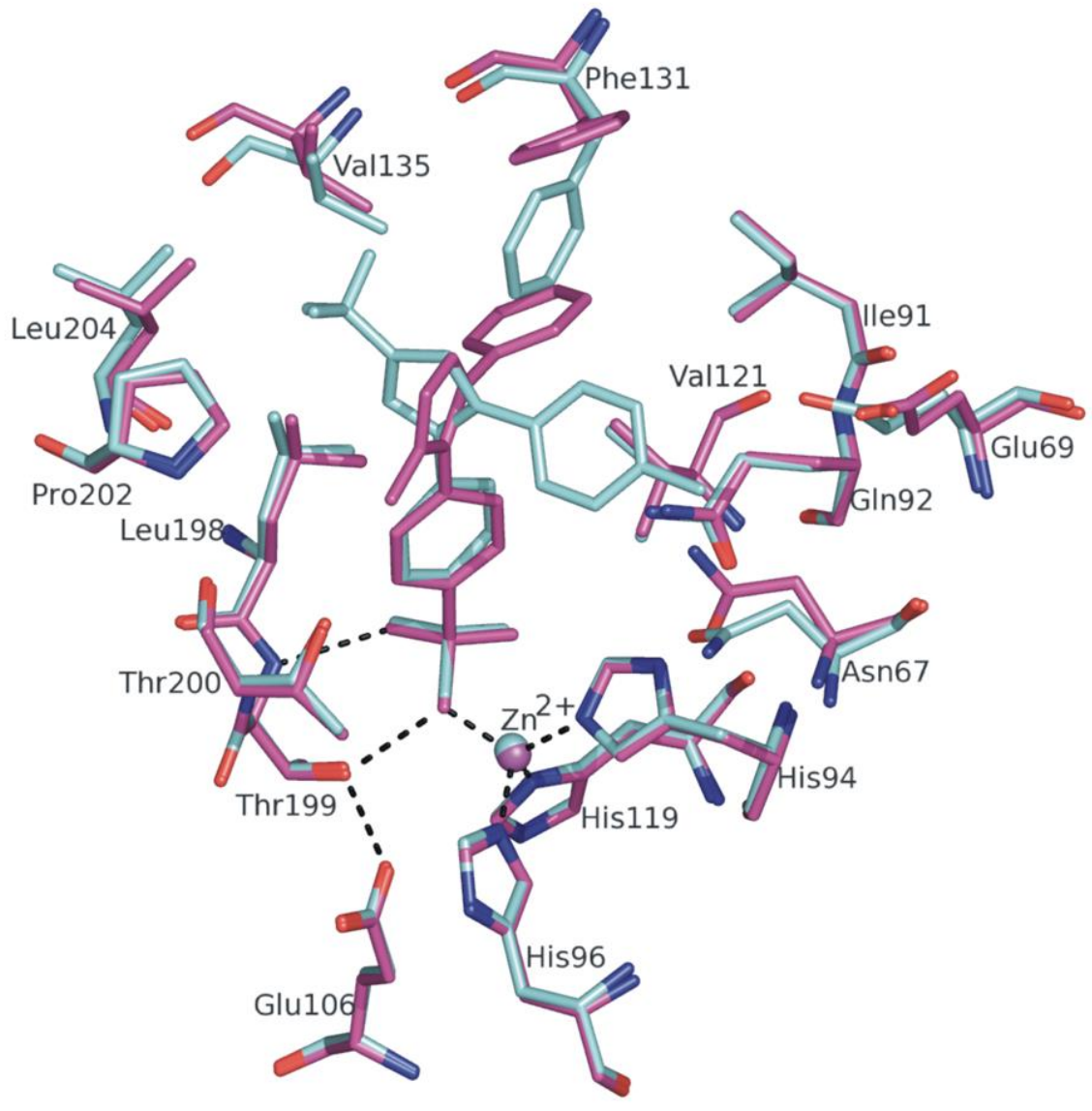

For example, as observed from these structures, the phenyl-isoxazole moiety of valdecoxib filled the active site channel of the enzyme and interacted with the side chains of Gln92, Val121, Leu198, Thr200 and Pro202 (distance $<4.5 \AA$ ). Besides these interactions, the 3phenyl group present in the inhibitor molecule was located into a hydrophobic cavity, simultaneously establishing van der Waals interactions with the aliphatic side chain of various hydrophobic residues (Val135,
Ile91, Val121, Leu198, Leu141) and a strong offset faceto-face stacking interaction with the aromatic ring of Phe131 [71]. Figure 3 shows a structural overlay of valdecoxib 15 [71] and celecoxib 14 [70] bound to hCA II, as determined by the superposition of hCA II active site residues. In both cases, the organic scaffold of the inhibitor (i.e., the isoxazole ring of $\mathbf{1 5}$, or the pyrazole ring of 14) did not establish polar interactions with the enzyme active site but participated to a large number of 
hydrophobic contacts. This similarity was reflected by a rather comparable value of the $\mathrm{K}_{\mathrm{I}}$ for the two inhibitors against hCA II (Table II). However, even though valdecoxib and celecoxib are structurally similar, they showed a very different location when bound to the enzyme active site. In fact, celecoxib completely filled the entire CA II active site, with its trifluoromethyl group in the hydrophobic part of the active site and the $p$-tolyl moiety in the hydrophilic one (and this may also explain why it is approximately a two times stronger hCA II inhibitor as compared to valdecoxib) [70,71]. Consequently, the $p$-tolyl moiety of celecoxib did not establish any interaction with the side chain of Phe131. In contrast to this, valdecoxib was rotated of about $90^{\circ}$ around the chemical bond connecting the benzensulfonamide and the substituted isoxazole ring. This rotation placed the 3-phenyl substituent of the inhibitor in a different position and allowed, together with the aforementioned movement of Phe131, the strong stacking interaction with this aromatic residue [71]. It was in fact recently demonstrated by Supuran's group that just this interaction with Phe131 (or its absence) orients the active site binding region of inhibitors within the hCA II cavity, allowing thus for further insights into the rational drug design of $\mathrm{CA}$ inhibitors [72].

The potent inhibition of physiologically relevant CA isozymes by the coxibs $\mathbf{1 4}$ and $\mathbf{1 5}$ affords for novel clinical applications. We have in fact showed that both celecoxib and valdecoxib are effective systemic antiglaucoma agents in hypertensive rabbits, possessing an activity similar to acetazolamide [70]. However, the two compounds also strongly inhibited the tumorassociated isoforms CA IX and XII (Table 2) [1,70,71] and there are many reports in the literature regarding the beneficial effects of mainly celecoxib in diverse cancer types [73-77]. Such effects may now be explained by a dual mechanism of action: in addition to COX-2 inhibition, these compounds also interfere with the activity of CA isozymes critical for the development and invasion of cancer cells, such as IX and XII. This additional mechanism is in fact observed only with the sulfonamide not methylsulfone COX-2 inhibitors [7377]. Thus, these two compounds may already be used clinically as antitumor agents and may constitute leads for developing potent antitumor sulfonamides possessing several mechanisms of antitumor action.

\section{Sulfonamide CAls as anticancer agents}

Indisulam 8 [78], a benzenesulfonamide derivative discovered by Owa's group was in clinical trials as an antitumor agent [1,4,78-80] and it also possesses significant CA inhibitory properties against many CA isoforms (Table II) The X-ray crystal structures of indisulam and sulpiride, another primary benzenesulfonamide drug in clinical use as an antipsychotic, in adduct with hCA II, have been reported by Supuran's group and were useful for drug design purposes of other sulfonamide CAIs [78,79]. However, indisulam is no longer being developed as an anticancer agent, probably due to the lack of significant effects in Phase II trials [80]. However, in the last decade, isoform CA IX and XII were validated as antitumor/antimetastatic drug targets as well as for the imaging hypoxic tumors [80-91]. Many CAIs which selectively inhibit these two isoforms, belong to sulfonamide, coumarin and sulfocoumarin classes of CAIs. Alone or in combination with other agents, CA IX/XII inhibitors inhibit the growth of the primary tumors, the formation of metastases and deplete the cancer stem cell population, three beneficial antitumor mechanisms, making them unique among all anticancer drugs available to date [80-92]. The compound which progressed to Phase II clinical trials as an antitumor/antimetastatic agent is SLC-0111 (compound 26) which was discovered in the Supuran's laboratory [83]. This benzenesulfonamide derivative is highly isoform selective for the tumor associated CA IX and XII, shows a good bioavailability and was effective alone or in combination with other anticancer drugs in both animal models and preliminary clinical trials $[80$, 83-92]. Many of its analogs were obtained and investigated in detail [84-88] as well as CAIs incorporating positron emitting isotopes for possible theragnostic applications, for the treatment and imaging of hypoxic tumors [89-91].

\section{Lacosamide, an antiepileptic with a strange binding mode to CAs}

Lacosamide, $(2 R)$-2-acetylamino- $N$-benzyl-3

methoxypropanamide, 27 , a relatively new antiepileptic 
drug recently approved for use in USA and Europe, in 2008, [93] seems to modulate the slow inactivation gate sodium channels and collapsin response mediator protein 2 as antiepileptic mechanisms, but high affinity binding targets for this drug have not been identified so far, even if 100 potential binding sites in various receptors have been investigated [93]. Thus, the cognate receptors/proteins with which the drug may interact in vivo are largely unknown, although a lot of interesting research was recently reported by its discoverers, Kohn's group [92]. Thus it was hypothesized that CAs might be a putative target of this new drug and its inhibitory activity against all mammalian isozymes was investigated [94]. Lacosamide $\mathbf{2 7}$ is a medium potency inhibitor of isoforms hCA I, II, III, IV, VB, VI, IX, XIV and mCA XV, with inhibition constants in the range of 331-525 nM. The remaining isozymes, i.e., hCA VA, VII, XII and XIII are less inhibited by this drug, with inhibition constants in the micromolar range $\left(\mathrm{K}_{\mathrm{IS}}\right.$ of 1.21 $-4.56 \mu \mathrm{M}$ ) [94]. However, the nice surprise came when the high-resolution X-ray crystal structure of this drug in complex with hCA II (Figure 4) was resolved [94].<smiles>[R6]c1cc2c(cc1S(N)(=O)=O)S(=O)(=O)N([R2])C([R3])N2</smiles>

19<smiles>CCC1NC(=O)c2cc(S(N)(=O)=O)c(Cl)cc2N1</smiles>

20<smiles>NS(=O)(=O)c1cc(C2(O)NC(=O)c3ccccc32)ccc1Cl</smiles>

22<smiles>NS(=O)(=O)c1cc(C(=O)O)c(NCc2ccco2)cc1Cl</smiles>

24 a: $\mathrm{R} 2=\mathrm{R} 3=\mathrm{H}, \mathrm{R} 6=\mathrm{Cl}$, Hydrochlorothiazide

b: $\mathrm{R} 2=\mathrm{R} 3=\mathrm{H}, \mathrm{R} 6=\mathrm{CF}_{3}$, Hydroflumethiazide

c: $\mathrm{R} 2=\mathrm{H}, \mathrm{R} 3=\mathrm{PhCH}_{2}, \mathrm{R} 6=\mathrm{CF}_{3}$, Bendroflumethiazide

d: $\mathrm{R} 2=\mathrm{H}, \mathrm{R} 3=\mathrm{CHCl}_{2}, \mathrm{R} 6=\mathrm{Cl}$, Trichloromethiazide

e: $\mathrm{R} 2=\mathrm{Me}, \mathrm{R} 3=\mathrm{CH}_{2} \mathrm{SCH}_{2} \mathrm{CF}_{3}, \mathrm{R} 6=\mathrm{Cl}$, Polythiazide<smiles>Cc1ccccc1N1C(=O)c2cc(S(N)(=O)=O)c(Cl)cc2NC1C</smiles>

21<smiles>CC1Cc2ccccc2N1NC(=O)c1ccc(Cl)c(S(N)(=O)=O)c1</smiles>

23<smiles>CCCCNc1cc(C(=O)O)cc(S(N)(=O)=O)c1Oc1ccccc1</smiles>

25 
<smiles>NS(=O)(=O)c1ccc(NC(=O)Nc2ccc(F)cc2)cc1</smiles>

26: SLC-0111<smiles>COCC(NC(C)=O)C(=O)NCc1ccccc1</smiles>

27<smiles>COc1cc2oc(=O)ccc2cc1C(O)CC(C)C</smiles>

28<smiles>COc1cc(O)c(/C=C\C(=O)O)cc1C(O)CC(C)C</smiles>

29<smiles>Cc1cn(-c2cc(NC(=O)c3ccc(C)c(Nc4nccc(-c5cccnc5)n4)c3)cc(C(F)(F)F)c2)cn1</smiles>

30

$$
\begin{aligned}
& K_{I}(\text { hCA I })=31.9 \mathrm{nM} \\
& K_{I}(\text { hCA II) }=30.2 \mathrm{nM}
\end{aligned}
$$$$
K_{I}(h C A ~ I)=29.3 n M
$$$$
\mathrm{K}_{\mathrm{I}}(\mathrm{hCA} \text { II) }=4.1 \mathrm{nM}
$$<smiles>Cc1ccc(Nc2nccc(N(C)c3ccc4c(C)n(C)nc4c3)n2)cc1S(N)(=O)=O</smiles>

32: pazopanib 
Figure 4. Superposition of the hCA II - hydrolyzed coumarin 29 (in blue sky) adduct (PDB file 3F8E) [21] with the hCA II - lacosamide 27 (yellow) adduct (PDB file 3IEO [94]). The $\mathrm{Zn}$ (II) ion is the central violet sphere with its three coordinated histidine residues (His94, 96, 119) shown, whereas the protein backbone is represented as green ribbon. Amino acid residues involved in the binding of inhibitors $\mathbf{2 7}$ and $\mathbf{2 9}$ are shown in detail (Thr200, Asn67, Gln92, and Phe131) in CPK colors

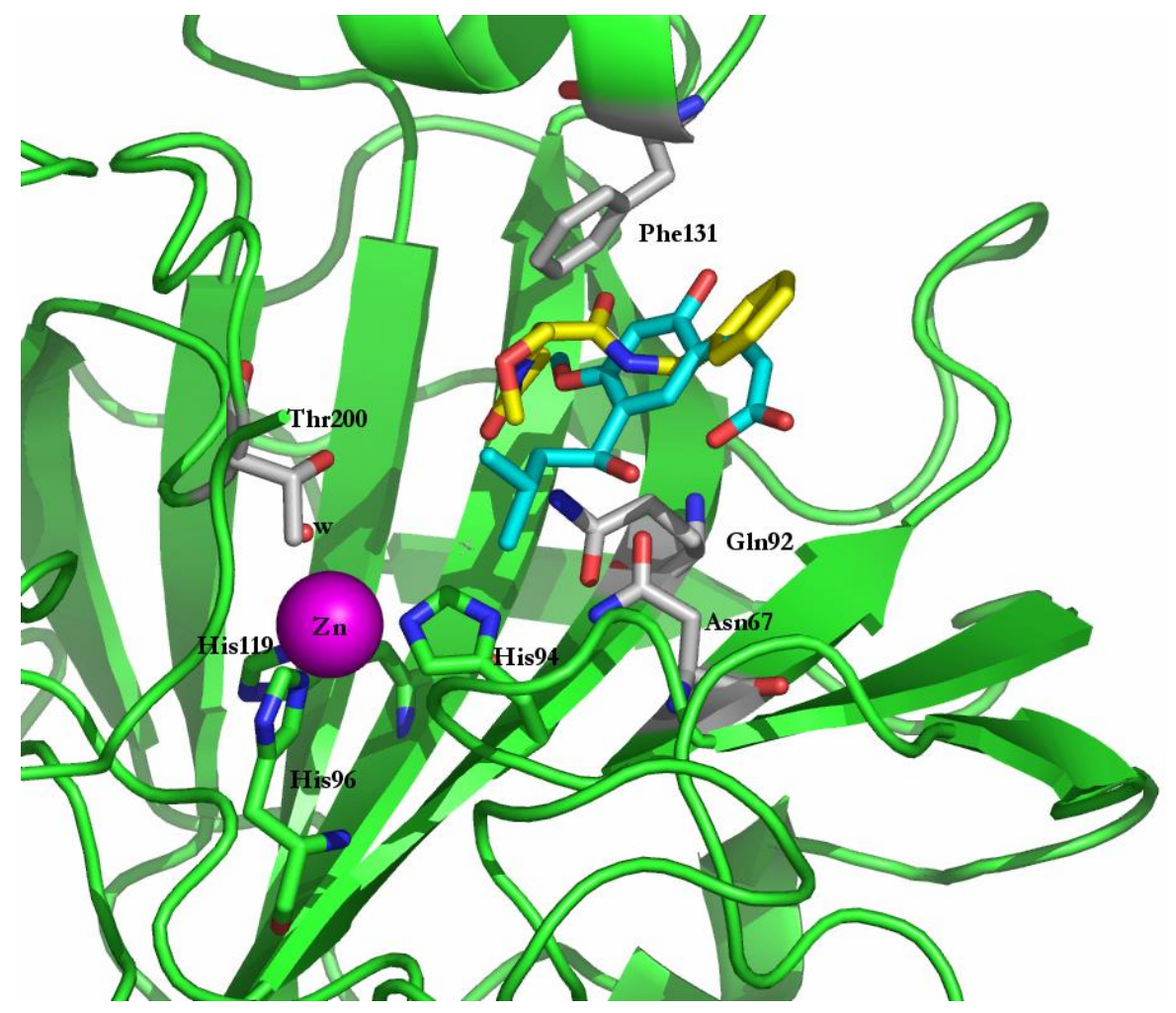

As for the previously reported structure of coumarin $\mathbf{2 8}$ in adduct with hCA II [21], when the hydrolyzed form 29 has been detected, it was demostrated that lacosamide does not interact with the metal ion from the bottom of the enzyme active site but is accommodated at its entrance (Fig. 4). This represents a completely new mechanism of CA inhibition [21,94]. All atoms of lacosamide $\mathbf{2 7}$ had clearly defined electron density in the hCA II - $\mathbf{2 7}$ adduct. Lacosamide adopted an extended conformation when bound to the hCA II active site, making no hydrogen bonds at all, but only hydrophobic, van der Waals interactions $(<4 \AA)$ with several amino acid residues, such as Thr200, Phe131, Gln92 and Asn67, known to interact with other classes of inhibitors (sulfonamides, sulfamates, coumarins) [24]. Indeed, the acetamido moiety of lacosamide was orientated towards Gln92, with the distance between the methyl group of the inhibitor and the $\mathrm{NH}_{2}$ moiety of Gln92 being of only
$2.2 \AA$. The methyl belonging to the methoxy moiety of lacosamide was on the other hand orientated towards Asn67, with a distance between the oxygen of the $\mathrm{CONH}_{2}$ moiety of Asn67 and the methyl of the inhibitor of $3.7 \AA$. Also, the $\mathrm{PhCH}_{2}$ fragment of lacosamide interacted with this amino acid residue, i.e., Asn67, with a distance of $4.0 \AA$ between the same carbonyl oxygen of the amino acid residue and the methylene moiety of 27. On the other hand, many atoms of the phenyl ring of Phe 131 were in van der Waals contacts with the CONH$\mathrm{CH}_{2}$ and phenyl fragments of lacosamide. Thr200 (the $\mathrm{OH}$ moiety) was also in van der Waals contact with the methoxy moiety of lacosamide, whereas the phenyl moiety of $\mathbf{2 7}$ was orientated towards the exit of the active site cavity, not making many interactions with other amino acids than Phe131 (from which it was anyhow at around $4-4.5 \AA$ ). Thus, this moiety of 27 might be derivatized in order to augment the affinity of the 
inhibitor for the CA active site. The stronger inhibitor 29 participates in many more polar interactions with various amino acid residues and water molecules from the hCA II active site, presumably because the four polar side chains substituting its phenyl ring (obtained after the hydrolysis of the coumarin $\mathbf{2 8}$ to the corresponding cis2-hydroxycinnamic acid derivative 29) allow the latter compound to participate in many other interactions compared to the unique side chain present in lacosamide 27 [21,94]. These data clearly show that lacosamide may be used as lead for designing CAIs with a new mechanism of action. As yet, it is not clear whether the rather significant CA inhibitory properties of this compound may explain some of its antiepileptic activity, but no detailed such studies have been performed so far.

\section{The protein tyrosine kinase inhibitors imatinib nilotinib and pazopanib strongly inhibit mammalian CA isoforms}

There are 518 protein kinases and approximately 100 protein phosphatases encoded within the human genome [95]. A major focus of cancer research in recent years has been to identify oncogenic molecules and the signal transduction pathways in which they are involved, in order to develop specifically targeted drugs. In cancer, as well as in other proliferative diseases, unregulated cell proliferation, differentiation and survival frequently results from abnormal protein phosphorylation. Receptor and non-receptor protein tyrosine kinases (PTKs) are essential enzymes in cellular signaling processes that regulate cell growth, differentiation, migration and metabolism [95]. Aberrant catalytic activity of many PTKs, via mutation or overexpression, plays an important role in numerous pathological conditions, the most important of which is cancer. PTKs associated with platelet-derived growth factor (PDGF) receptors, Abelson (ABL) protein, KIT protein (also known as stem cell factor $[\mathrm{SCF}]$ receptor), protein kinase AI (PKAI), bcl-2/bcl-xL, FLT3 (fms-related tyrosine kinase/Flk2/Stk-2) - a receptor tyrosine kinase primarily expressed on hematopoietic cells, epidermal growth factor receptor (EGFR), and ErbB-2 transmembrane tyrosine kinases are currently being targeted by various compounds/drugs in the treatment of cancer [95]. The first tyrosine kinase inhibitor to be used clinically, imatinib 30 (as mesylate salt) (Glivec ${ }^{\mathrm{TM}} / \mathrm{Gleevec}^{\mathrm{TM}}$, Novartis Pharmaceuticals) blocks activity of the Bcr-Abl oncoprotein and the cell trtansmembrane tyrosine kinase receptor c-Kit, and was recently approved for several indications in the treatment on chronic myeloid leukemia (CML) and gastrointestinal stromal tumors (GIST). In both of these examples the target protein was identified by an oncogenic, activating mutation. Imatinib $\mathbf{3 0}$ is also a potent inhibitor of PDGFR kinase and is currently being employed for the treatment of chronic myelomonocytic leukemia and is being evaluated in glioblastoma multiforme, based upon evidence in these diseases of activating mutations in PDGFR. The molecular pathogenesis of CML in particular, depends on formation of the $B c r-A b l$ oncogene, leading to constitutive expression of the tyrosine kinase fusion protein, Bcr-Abl. Based on these observations, imatinib was developed as a selective inhibitor of the Bcr-Abl protein tyrosine kinase. The extraordinary success of imatinib in CML and GIST represents a model for molecularly targeted therapy for tumors, whereas the molecular basis and the detailed mechanisms of action of this drug are still not completely understood at this moment $[95,96]$. Nilotinib 31, is a second-generation PTK inhibitor (PTKI) and was approved in 2007, for the treatment of adult patients with chronic-phase and accelerated-phase Philadelphia chromosome-positive $(\mathrm{Ph}+) \mathrm{CML}$, resistant to or intolerant of prior treatment that included imatinib. The compound is also being investigated for the treatment of patients with GIST [96]. Serendipitously, the potential of imatinib $\mathbf{3 0}$ and nilotinib $\mathbf{3 1}$ to act as inhibitors of all the catalytically active mammalian CA isoforms has been recently discovered [96]. Thus, imatinib and nilotinib were observed to act as very potent inhibitors of two CA isozymes, i.e., hCA I and II, with inhibition constants in the range of $4.1-31.9 \mathrm{nM}$. The isoform with the highest affinity for these drugs was the ubiquitous, physiologically dominant hCA II. In fact, the clinically used sulfonamide inhibitor par excellence, acetazolamide 1, has a $\mathrm{K}_{\mathrm{I}}$ of $12 \mathrm{nM}$ against hCA II, intermediate between that of nilotinib $\left(\mathrm{K}_{\mathrm{I}}\right.$ of $\left.4.1 \mathrm{nM}\right)$ and imatinib ( $\mathrm{K}_{\mathrm{I}}$ of $30.2 \mathrm{nM}$ ) [1,96]. Effective inhibition with imatinib and nilotinib was also observed against the 
cytosolic isoform, hCA VII, the tumor-associated, transmembrane enzyme, hCA IX, and the membraneanchored enzyme mCA XV [96]. These isoforms were inhibited by the two compounds with $\mathrm{K}_{\mathrm{I}} \mathrm{S}$ in the range of $41.9-109 \mathrm{nM}$. The two PTKIs showed $\mathrm{K}_{\mathrm{I}}$ of $99-109$ $\mathrm{nM}$ against the preponderantly brain-associated hCA VII, being less active than acetazolamide ( $\mathrm{K}_{\mathrm{I}}$ of $\left.2.5 \mathrm{nM}\right)$. hCA IX is one of the most promising new anticancer drug targets as recently shown [1-4]. The development of agents targeting this isozyme may have clinical and diagnostic significance for the management of hypoxic tumors in which CA IX is generally overexpressed [1]. It has been observed that imatinib and nilotinib significantly inhibited this isoform, with inhibition constants of $41.9-75.7 \mathrm{nM}$, in the same range as the sulfonamide acetazolamide $\mathbf{1}\left(\mathrm{K}_{\mathrm{I}}\right.$ of $\left.25 \mathrm{nM}\right)$. It might be hypothesized that part of the excellent anticancer effects of these drugs may also be due to their interaction with this or other CA isoforms involved in carcinogenesis. The affinity of the two drugs (imatinib and nilotinib) for mCA XV on the other hand is very similar to that of acetazolamide, the three compounds showing $\mathrm{K}_{\mathrm{I}} \mathrm{s}$ of 72 $-79 \mathrm{nM}$. A third group of CA isozymes, including hCA III (cytosolic), VI (secreted in saliva and milk), XII (transmembrane, present in some tumors among other tissues) and XIV (transmembrane) were moderately inhibited by imatinib and nilotinib, with $\mathrm{K}_{\mathrm{I}}$ in the range of 223 - $980 \mathrm{nM}$ [96]. The membrane-bound hCA IV was also inhibited moderately by nilotinib $\left(\mathrm{K}_{\mathrm{I}}\right.$ of 446 $\mathrm{nM})$ but much less by imatinib ( $\mathrm{K}_{\mathrm{I}}$ of $\left.4553 \mathrm{nM}\right)$. The mitochondrial isoforms hCA VA and $\mathrm{VB}$, together with the slow cytosolic isoform mCA XIII showed the weakest inhibition with the PTKIs $\mathbf{3 0}$ and 31, with inhibition constants in the range of 4,665-20,200 nM.

Given the systemic exposures achieved at the standard recommended doses of both imatinib (steady state $\mathrm{C}_{\max } /$ $\mathrm{C}_{\min } 5.2$ and $2.5 \mu \mathrm{M}$ at $400 \mathrm{mg}$ q.d.) and nilotinib (steady state $\mathrm{C}_{\max } / \mathrm{C}_{\min } 4.0$ and $1.8 \mu \mathrm{M}$ at $400 \mathrm{mg}$ b.i.d.), it seems likely that the inhibition of at least some of the CAs, alone or in concert with one another, by these drugs might be physiologically relevant [96]. Thus for example, CA IX and CA XII promote tumor cell survival within the hypoxic tumor microenvironment, and therefore their inhibition by imatinib and nilotinib might contribute to the efficacy of these drugs in GIST. Some other effects of these drugs might also be related to CA inhibition. Thus, CAs are known to play a pivotal role in bone metabolism, and acetazolamide inhibits bone resorption in vitro/ex vivo [14], being shown to be effective for the long-term therapy of osteoporosis. Therefore, the recently reported long-term effect of imatinib therapy in promoting bone formation in CML patients, mimicks quite well the action of acetazolamide observed in the same clinical settings, and might be related to CA II inhibition in in osteoclasts and osteoblasts, in addition to the inhibition of kinases $[14,96]$. It is in fact well-known that several CA isozymes (CA II, CA XII and XIV) are involved in the acidification processes in osteoclasts, leading to inorganic matrix dissolution that precedes enzymatic removal of the organic bone matrix [14]. By inhibiting these CA isozymes with sulfonamides, the osteoclasts acidification and bone dissolution processes are also inhibited [14].

Thus, the two clinically used PTKIs, imatinib and nilotinib were recently shown as inhibitors of many CA isoforms. The two compounds inhibited all 13 catalytically active mammalian isoforms with $\mathrm{K}_{\mathrm{I}} \mathrm{S}$ in the range of $4.1 \mathrm{nM}-20.2 \mu \mathrm{M}$. CA I and CA II were the most efficiently inhibited isoforms $\left(\mathrm{K}_{\mathrm{IS}}\right.$ of $4.1-31.9$ $\mathrm{nM}$ ), whereas CA VA and VB showed the lowest affinity for these drugs $\left(\mathrm{K}_{\mathrm{I}} \mathrm{s}\right.$ of $\left.5.4-20.2 \mu \mathrm{M}\right)$. The anticancer activity of the two PTKIs investigated here may also involve their interaction with CAs in addition to the targets for which they were designed originally, i.e., the PTKs. Furthermore, they afford CAIs with a completely novel chemotype, although the detailed binding mode of the two compounds to CAs is unknown for the moment, due to the fact that no god X-ray crystal structure of one of their adducts could be obtained so far. However, the proposed inhibition CA mechanism with PTKIs is depicted in Figure 5.

The inhibitor appears to be anchored to the $\mathrm{Zn}$ (II) coordinated water molecule from the hCA II active site, similarly to spermine, an amine inhibitor for which the $\mathrm{X}$-ray crystal structure has recently been reported by Supuran's group [20] (Figure 5A). Alternatively, 
imatinib might not interact with the metal ion or its nonprotein ligand, but might be anchored towards the entrance of the active site, similarly to the coumarin CAIs or lacosamide [21,94] (Figure 5B).

Figure 5. Proposed CA inhibition mechanisms with the PTKI imatinib 27.30. A. The inhibitor is anchored to the $\mathrm{Zn}$ (II) coordinated water molecule from the hCA II active site. B. The inhibitor does not interact with the metal ion or its non-protein ligand, but is anchored towards the entrance of the active site, similarly to the coumarin CAIs or lacosamide [21,94]. The $\mathrm{Zn}(\mathrm{II})$ ion is coordinated by three His residues (His94, 96 and 119). The gate-keeper residues Thr199 (making a hydrogen bond with the fourth zinc ligand) is also shown [1].

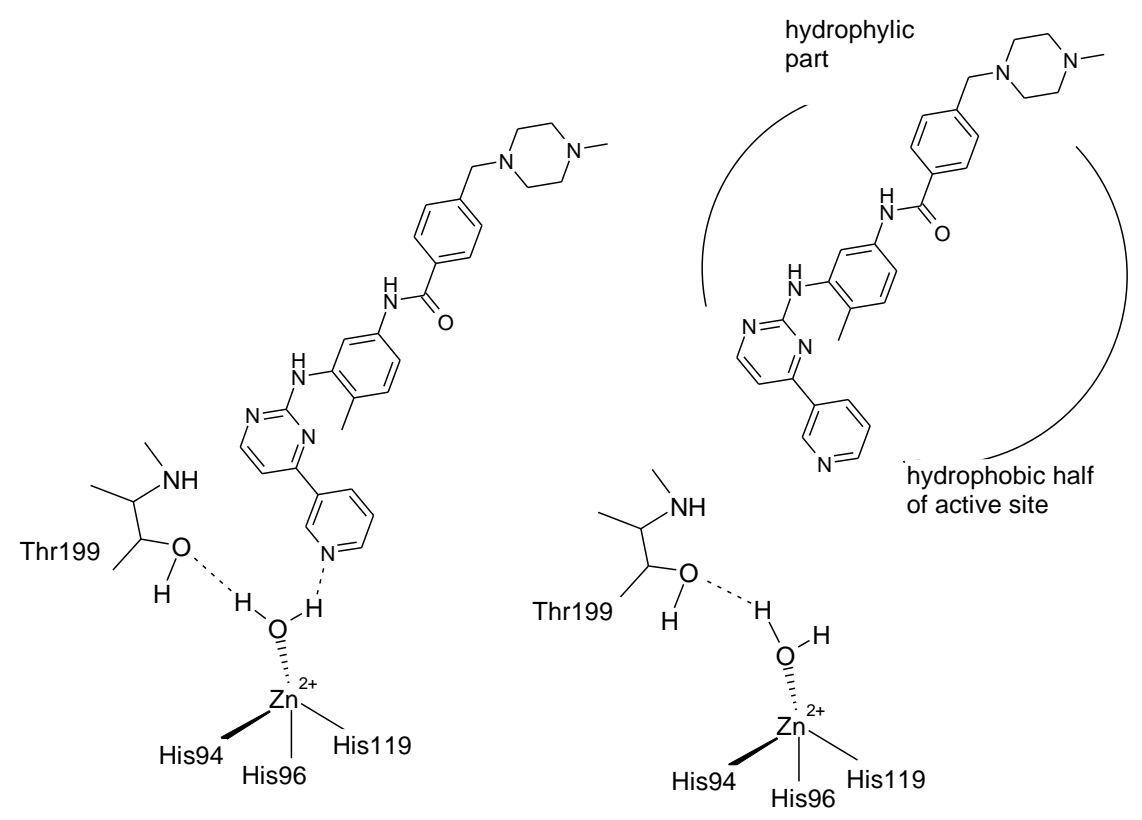

Pazopanib 32 on the other hand is a primary sulfonamide derivative [97]. It is a multi-targeted tyrosine kinase inhibitor (TKI) used clinically for the treatment of several types of tumors [97]. Pazopanib, similar to structurally related sulfonamides such as indisulam, acetazolamide or ureido-substituted benzenesulfonamides (SLC-0111) acts as a low nanomolar inhibitor of many of the fifteen human isoforms hCA I-XIV. Such data indicate that in addition to the TK inhibitory action, pazopanib exerts its antitumor/antimetastatic effects also due to the potent inhibition of the tumor-associated, hypoxia-inducible enzymes CA IX and XII [97].

\section{Conclusions}

With their diffuse distribution in many tissues in vertebrates, the 16 different $\alpha$-CA isoforms play crucial physiological roles. These enzymes are efficient catalysts for the reversible hydration of carbon dioxide to bicarbonate, and are inhibited by several classes of compounds such as the sulfonamides and their isosteres (sulfamates, sulfamides etc.), phenols, coumarins and polyamines. At least 25 clinically used drugs or agents in clinical development show significant inhibitory activity against the mammalian (human, h) CA isoforms. Such compounds have applications as diuretics antiglaucoma drugs, and anticonvulsants, whereas some compounds are being developed as anticancer agents/diagnostic tools for tumors, or as antiobesity agents. The presence of these ubiquitous enzymes in so many tissues and in so different isoforms, represents an 
attractive goal for the design of inhibitors/activators with biomedical applications but also rises challenging problems for polypharmacology related issues. The examples provided here for drugs such as topiramate, zonisamide, lacosamide, the sulfonamide coxibs (celecoxib, valdecoxib), or for the tyrosine kinase inhibitors imatinib, nilotinib and pazopanib, show that these agents probably exert their pharmacological activity also due to inhibition of some CA isoforms, in addition to the targets for which they have been originally designed. Such off-target action affords for novel applications of some of these compounds, such as for example the antiobesity action of topiramate and zonisamide (thought to be due to inhibition of two mitochondrial CA isoforms, CA VA and VB) or the antitumor activity of the coxibs and other sulfonamide CAIs, which strongly inhibit the tumor-associated isoforms CA IX and XII. Furthermore, lacosamide, imatinib and nilotinib constitute CAIs of a completely novel chemotype and may lead both to novel applications for these drugs as well as to the development of CAIs possessing a novel mechanism of action compared to the sulfonamides. Thus, emerging novel drug targets or novel applications can be discovered by attentively considering such off-target activity of some well-known drugs.

\section{Conflict of Interest}

I have no conflict of interests and the opinions are of my own.

\section{References}

1. Supuran, C.T. (2008) Carbonic anhydrases: novel therapeutic applications for inhibitors and activators. Nature Revi. Drug Discov., 7, 168-181.

2. Supuran C.T. (2018) Carbonic anhydrase inhibitors and their potential in a range of therapeutic areas. Expert Opin. Ther. Pat., 28, 709-712

3. Pastorekova, S., Parkkila, S., Pastorek, J., Supuran, C.T. (2004) Carbonic anhydrases: current state of the art, therapeutic applications and future prospects. J. Enzyme Inhib. Med. Chem., 19, 199-229.

4. Supuran CT. (2016) Structure and function of carbonic anhydrases. Biochem. J., 473, 2023-2032

5. Supuran, C.T. (2016) How many carbonic anhydrase inhibition mechanisms exist? J. Enzyme Inhib. Med. Chem., 31, 345-360.
6. Supuran, C.T. (2008) Diuretics: From classical carbonic anhydrase inhibitors to novel applications of the sulfonamides. Curr. Pharm. Des., 14, 641 - 648.

7. De Simone, G., Di Fiore, A., Supuran, C.T. (2008) Are carbonic anhydrase inhibitors suitable for obtaining antiobesity drugs ? Curr. Pharm. Des., 14, 655-660

8. Supuran CT. (2017) Advances in structure-based drug discovery of carbonic anhydrase inhibitors. Expert Opin. Drug Discov., 12, 61-88

9. Del Prete, S., Vullo, D., Fisher, G.M., Andrews, K.T., Poulsen, S.A., Capasso, C., Supuran, C.T. (2014) Discovery of a new family of carbonic anhydrases in the malaria pathogen Plasmodium falciparum--the $\eta$-carbonic anhydrases. Bioorg. Med. Chem. Lett. 24, 4389-4396.

10. Alterio, V., Hilvo, M., Di Fiore, A., Supuran, C.T., Pan, P., Parkkila, S., Scaloni, A., Pastorek, J., Pastorekova, S., Pedone, C., Scozzafava, A., Monti, S.M., De Simone, G. (2009) Crystal structure of the extracellular catalytic domain of the tumor-associated human carbonic anhydrase IX. Proc. Natl. Acad. Sci. USA, 106, 16233 - 16238.

11. Nishimori, I., Minakuchi, T., Onishi, S., Vullo, D., Scozzafava, A., Supuran, C.T. (2007) Carbonic anhydrase inhibitors. DNA cloning, characterization and inhibition studies of the human secretory isoform VI, a new target for sulfonamide and sulfamate inhibitors. J. Med. Chem., 50, 381-388

12. Vullo, D., Voipio J., Innocenti, A., Rivera, C., Ranki, H., Scozzafava, A., Kaila, K., Supuran, C.T. (2005) Carbonic anhydrase inhibitors. Inhibition of the human cytosolic isozyme VII with aromatic and heterocyclic sulfonamides. Bioorg. Med. Chem. Lett., 15, 971-976

13. Supuran, C.T.; Casini, A.; Scozzafava, A. (2004) Development of sulfonamide carbonic anhydrase inhibitors. In Carbonic anhydrase - Its inhibitors and activators, Supuran, C.T., Scozzafava, A., Conway, J. (Eds.); CRC Press, Boca Raton (FL), USA, pp. 67-148.

14. Riihonen, R., Supuran, C.T., Parkkila, S., Pastorekova, S., Vaananen, H.K., Laitala-Leinonen, T. (2007) Membranebound carbonic anhydrases in osteoclasts. Bone, 40, 10211031

15. Svastova, E., Hulikova, A., Rafajova, M., Zatovicova, M., Gibadulinova, A., Casini, A., Cecchi, A., Scozzafava, A., Supuran, C.T., Pastorek, J., Pastorekova, S. (2004) Hypoxia activates the capacity of tumor-associated carbonic anhydrase IX to acidify extracellular $\mathrm{pH}$. FEBS Lett., 577, 439-445.

16. Supuran, C.T. (2016) Carbonic anhydrase inhibition and the management of neuropathic pain. Expert Rev. Neurother., 16, 961-968.

17. Di Cesare Mannelli, L., Micheli, L., Carta, F., et al. (2016) Carbonic anhydrase inhibition for the management of cerebral ischemia: in vivo evaluation of sulfonamide and 
coumarin inhibitors. J. Enzyme Inhib. Med. Chem., 31, 894-899

18. Margheri, F., Ceruso, M., Carta, F., Laurenzana, A., Maggi, L., Lazzeri, S., Simonini, G., Annunziato, F., Del Rosso, M., Supuran, C.T., Cimaz, R. (2016) Overexpression of the transmembrane carbonic anhydrase isoforms IX and XII in the inflamed synovium. J. Enzyme Inhib. Med. Chem., 31(sup4), 60-63.

19. a) Innocenti, A., Vullo, D., Scozzafava, A., Supuran, C.T. (2008) Carbonic anhydrase inhibitors. Inhibition of mammalian isoforms I - XIV with a series of substituted phenols including paracetamol and salicylic acid. Bioorg. Med. Chem., 16, 7424-7428; b) Innocenti, A., Vullo, D. Scozzafava, A., Supuran, C.T. (2008) Carbonic anhydrase inhibitors. Interactions of phenols with the 12 catalytically active mammalian isoforms (CA I - XIV). Bioorg. Med. Chem. Lett., 18, 1583-1587.

20. Temperini, C., Innocenti, A., Scozzafava, A., Kaila, K., Supuran, C.T. (2010) . Polyamines inhibit carbonic anhydrases by a new mechanism of action, anchoring to the zinc-coordinated water molecule. J. Med.Chem. 53, in press.

21. Maresca, A., Temperini, C., Vu, H., Pham, N.B., Poulsen, S.A., Scozzafava, A., Quinn, R.J., Supuran, C.T. (2009) Non-zinc mediated inhibition of carbonic anhydrases: coumarins are a new class of suicide inhibitors. J. Am. Chem. Soc., 131, 3057-3062.

22. Maresca, A., Temperini, C., Pochet, L., Masereel, B., Scozzafava, A., Supuran, C.T. (2010) Deciphering the mechanism of carbonic anhydrase inhibition with coumarins and thiocoumarins. J. Med. Chem., 53, 335 344.

23. Innocenti, A., Durdagi, S., Doostdar, N., Strom, T.A., Barron, A.R., Supuran, C.T. (2010) Nanoscale enzyme inhibitors: Fullerenes inhibit carbonic anhydrase by occluding the active site entrance. Bioorg. Med. Chem., 18, in press (doi:10.1016/j.bmc.2010.03.026.)

24. Alterio, V., Di Fiore, A., D’Ambrosio, K., Supuran, C.T., De Simone, G. (2009) X-Ray crystallography of CA inhibitors and its importance in drug design. In Drug Design of Zinc-Enzyme Inhibitors: Functional, Structural, and Disease Applications, Supuran, C.T.; Winum, J.Y. Eds., Wiley, Hoboken, pp. 73 - 138.

25. Temperini, C., Innocenti, A., Mastrolorenzo, A., Scozzafava, A., Supuran, C.T. (2007) Carbonic anhydrase inhibitors. Interaction of the antiepileptic drug sulthiame with twelve mammalian isoforms: kinetic and X-ray crystallographic studies. Bioorg. Med. Chem. Lett., 17, 4866-72.

26. De Simone, G., Di Fiore, A., Menchise, V., Pedone, C., Antel, J., Casini, A., Scozzafava, A., Wurl, M., Supuran, C.T.(2005) Carbonic anhydrase inhibitors. Zonisamide is an effective inhibitor of the cytosolic isozyme II and mitochondrial isozyme V: solution and X-ray crystallographic studies. . Bioorg. Med. Chem. Lett., 15, 2315-2320.

27. Abbate, F., Winum, J.Y., Potter, B.V., Casini, A., Montero, J.L., Scozzafava, A., Supuran, C.T. (2004) Carbonic anhydrase inhibitors: X-ray crystallographic structure of the adduct of human isozyme II with EMATE, a dual inhibitor of carbonic anhydrases and steroid sulfatase. Bioorg. Med. Chem. Lett., 14, 231-234.

28. Winum, J.Y., Temperini, C., El Cheikh, K., Innocenti, A., Vullo, D., Ciattini, S., Montero, J.L., Scozzafava, A., Supuran, C.T. (2006) Carbonic anhydrase inhibitors: clash with Ala65 as a means for designing inhibitors with low affinity for the ubiquitous isozyme II, exemplified by the crystal structure of the topiramate sulfamide analogue. J. Med. Chem., 49, 7024-7031.

29. Casini, A., Antel, J., Abbate, F., Scozzafava, A., David, S., Waldeck, H., Schäfer, S., Supuran, C.T. (2003) Carbonic anhydrase inhibitors: SAR and X-ray crystallographic study for the interaction of sugar sulfamates/sulfamides with isozymes I, II and IV. . Bioorg. Med. Chem. Lett. 13, 841-845.

30. Lopez, M., Paul, B., Hofmann, A., Morizzi, J., Wu, Q., Charman, S.A., Innocenti, A., Vullo, D., Supuran, C.T., Poulsen, S.-A. (2009) S-glycosyl primary sulfonamides a new structural class for selective inhibition of cancerassociated carbonic anhydrases. J. Med. Chem., 52, 64216432.

31. Alterio, V., Monti, S.M., Truppo, E.; Pedone, C., Supuran, C.T., De Simone, G. (2010) The first example of significant active site conformational rearrangement in a carbonic anhydrase-inhibitor adduct: the carbonic anhydrase I-topiramate complex. Org. Biomol. Chem. in press.

32. Vitale, R. M., Pedone, C., Amodeo, P., Antel, J., Wurl, M., Scozzafava, A., Supuran, C.T., De Simone, G. (2007) Molecular modeling study for the binding of zonisamide and topiramate to the human mitochondrial carbonic anhydrase isoform VA. Bioorg. Med. Chem., 15, 41524158.

33. Maryanoff, B.E., Nortey, S.O., Gardocki, J.F., Shank, R.P., Dodgson, S.P. (1987) Anticonvulsant O-alkyl sulfamates. 2,3:4,5-Bis-O-(1-methylethylidene)-beta-Dfructopyranose sulfamate and related compounds. J. Med. Chem., 30, 880-887.

34. Maryanoff, B.E., Costanzo, M.J., Nortey, S.O., Greco, M.N., Shank, R.P., Schupsky, J.J., Ortegon, M.P., Vaught, J.L. (1998) Structure-activity studies on anticonvulsant sugar sulfamates related to topiramate. Enhanced potency with cyclic sulfate derivatives. J. Med. Chem., 41, 13151343.

35. Shank, R.P., Gardocki, J.F., Vaught, J.L., Davis, C.B., Schupsky, J.J., Raffa, R.B., Dodgson, S.J., Nortey, O., 
Maryanoff, B.E. (1994) Topiramate: preclinical evaluation of structurally novel anticonvulsant. Epilepsia, 35, 450460.

36. Sills, G.J., Leach, J.P., Kilpatrick, W.S., Fraser, C.M., Thompson, G.G., Brodie, M.J. (2000) Concentrationeffect studies with topiramate on selected enzymes and intermediates of the GABA shunt. Epilepsia, 41, S30-S34.

37. Rosenfeld WE. (1997) Topiramate: a review of preclinical, pharmacokinetic, and clinical data. Clin. Ther., 19, 12941308.

38. Herrero, A.I., Del Olmo, N., Gonzalez-Escalada, J.R., Solis, J.M. (2002) Two new actions of topiramate: inhibition of depolarizing GABAA - mediated responses and activation of a potassium conductance. Neuropharmacol., 42, 210-220.

39. Kuzniecky, R., Ho, S., Pan, J., Martin, R., Gilliam, F., Faught, E., Hetherington, H. (2002) Modulation of cerebral GABA by topiramate, lamotrigine, and gabapentin in healthy adults. Neurology, 58, 368-372.

40. Reis, J., Tergau, F., Hamer, H.M., Muller, H.H., Knake, S., Fritsch, B., Oertel, W.H., Rosenow, F. (2002) Topiramate selectively decreases intracortical excitability in human motor cortex. Epilepsia, 43, 1149-1156.

41. Gibbs, J.W. 3rd, Sombati, S., DeLorenzo, R.J., Coulter, D.A. (2000) Cellular actions of topiramate: blockade of kainate-evoked inward currents in cultured hippocampal neurons. Epilepsia, 41, S10-S16.

42. Skradski, S., White, H.S. (2000) Topiramate blocks kainate-evoked cobalt influx into cultured neurons. Epilepsia, 41, S45-47.

43. Zullino, D.F., Krenz, S., Besson, J. (2003) AMPA blockade may be the mechanism underlying the efficacy of topiramate in PTSD. J. Clin. Psych., 64, 219-220.

44. McLean, M.J., Bukhari, A.A., Wamil, A.W. (2000) Effects of topiramate on sodium-dependent action-potential firing by mouse spinal cord neurons in cell culture. Epilepsia, 41, S21-S24.

45. Taverna, S., Sancini, G., Mantegazza, M., Franceschetti, S., Avanzini, G. (1999) Inhibition of transient and persistent $\mathrm{Na}+$ current fractions by the new anticonvulsant topiramate. J. Pharmacol. Exp. Ther., 288, 960-968.

46. Perucca, E. (1997) A pharmacological and clinical review on topiramate, a new antiepileptic drug. Pharmacol. Res., 35, 241-256.

47. Masereel, B., Rolin, S., Abbate, F., Scozzafava, A., Supuran, C.T. (2002) Carbonic anhydrase inhibitors: anticonvulsant sulfonamides incorporating valproyl and other lipophilic moieties. J. Med. Chem., 45, 312-320.

48. Dodgson, S.J., Shank, R.P., Maryanoff, B.E. (2000) Topiramate as an inhibitor of carbonic anhydrase isoenzymes. Epilepsia, 41, S35-S39.
49. Fakhoury, T., Murray, L., Seger, D., McLean, M., AbouKhalil, B. (2002) Topiramate Overdose: Clinical and Laboratory Features. Epilepsy Behav., 3, 185-189.

50. Kuo, R.L., Moran, M.E., Kim, D.H., Abrahams, H.M., White, M.D., Lingeman, J.E. (2002) Topiramate-induced nephrolithiasis. J. Endourol., 16, 229-231.

51. Ribacoba Montero, R., Salas Puig, X. (2002) Efficacy and tolerability of long term topiramate in drug resistant epilepsy in adults. Rev. Neurol., 34, 101-105.

52. Aribi, A.M., Stringer, J.L. (2002) Effects of antiepileptic drugs on extracellular $\mathrm{pH}$ regulation in the hippocampal CA1 region in vivo. Epilepsy Res, 49, 143-151.

53. Stringer, J.L. (2000) A comparison of topiramate and acetazolamide on seizure duration and paired-pulse inhibition in the dentate gyrus of the rat. Epilepsy Res., 40, 147-153.

54. Leppik, I. E. (2004) Zonisamide: chemistry, mechanism of action, and pharmacokinetics. Seizure, 13 Suppl 1, S5-9

55. Ito, T., Hori, M., Masuda, Y., Yoshida, K., Shimizu, M. (1980) 3-Sulfamoylmethyl-1,2-benzisoxazole, a new type of anticonvulsant drug. Electroencephalographic profile. Arzneimittelforschung, 30, 603-609.

56. Masuda, Y., Karasawa, T. (1993) Inhibitory effect of zonisamide on human carbonic anhydrase in vitro. Arzneimittelforschung, 43, 416-418.

57. Masuda, Y., Noguchi, H., Karasawa, T. (1994) Evidence against a significant implication of carbonic anhydrase inhibitory activity of zonisamide in its anticonvulsive effects. Arzneimittelforschung, 44, 267-269.

58. Matsumoto, K., Miyazaki, H., Fujii, T., Hashimoto, M. (1989) Binding of sulfonamides to erythrocytes and their components. Chem Pharm Bull (Tokyo), 37, 1913-5.

59. De Simone, G., Scozzafava, A., Supuran, C.T. (2009) Which carbonic anhydrases are targeted by the antiepileptic sulfonamides and sulfamates ? Chem. Biol. Drug. Des., 74, 317-321

60. Lynch, C.J., Fox, H., Hazen, S.A., Stanley, B.A., Dodgson, S.J., Lanoue, K.F. (1995) Role of hepatic carbonic anhydrase in de novo lipogenesis. Biochem. J. 310, 197202.

61. Gordon A, Price .H. (1999) Mood stabilization and weight loss with topiramate. Am. J. Psychiatry, 156, 968-969.

62. Kim, C.S. (2003) Zonisamide effective for weight loss in women. J. Fam Pract., 52, 600-601.

63.63. Gadde, K.M., Franciscy, D.M., Wagner, H.R. 2nd, Krishnan, K.R. (2003) Zonisamide for weight loss in obese adults: a randomized controlled trial. JAMA, 289, 18201825.

64. Narula, P.K., Rehan, H.S., Unni, K.E.S., Gupta N. (2010) Topiramate for prevention of olanzapine associated weight gain and metabolic dysfunction in schizophrenia: A double-blind, placebo-controlled trial. Schizophrenia Res., 118, 218-223. 
65. Picard F, Deshaies Y, Lalonde J, Samson P, Richard D. (2000) Topiramate reduces energy and fat gains in lean $(\mathrm{Fa} /$ ?) and obese (fa/fa) Zucker rats. Obesity Res., 8, 656663.

66. Smith, S.M., Meyer, M., Trinkley, K.E. (2013) Phentermine/topiramate for the treatment of obesity. Ann. Pharmacother. 47, 340-349.

67. Supuran, C.T., Casini, A., Mastrolorenzo, A., Scozzafava, A. (2004) COX-2 selective inhibitors, carbonic anhydrase inhibition and anticancer properties of sulfonamides belonging to this class of pharmacological agents. Mini. Rev. Med. Chem., 4, 625-32

68. FitzGerald, G.A. (2003) COX-2 and beyond: Approaches to prostaglandin inhibition in human disease. Nat. Rev. Drug. Discov. 2, 879-90

69. Dogné, J.-M., Supuran, C.T., Pratico, D. (2005) Adverse cardiovascular effects of the coxibs. J. Med. Chem., 48, 2251-2257

70. Weber, A., Casini, A., Heine, A., Kuhn, D., Supuran, C.T., Scozzafava, A., Klebe, G. (2004) Unexpected nanomolar inhibition of carbonic anhydrase by COX-2-selective celecoxib: new pharmacological opportunities due to related binding site recognition J. Med. Chem., 47, 550557.

71. Di Fiore, A., Pedone, C., D'Ambrosio, K., Scozzafava, A., De Simone, G., Supuran, C.T. (2006) Carbonic anhydrase inhibitors: Valdecoxib binds to a different active site region of the human isoform II as compared to the structurally related cyclooxygenase II "selective" inhibitor celecoxib. Bioorg. Med. Chem. Lett., 16, 437-42.

72. Menchise, V., De Simone, G., Alterio, V., Di Fiore, A., Pedone, C., Scozzafava, A., Supuran, C.T. (2005) Carbonic anhydrase inhibitors: Stacking with Phe131 determines active site binding region of inhibitors as exemplified by the X-ray crystal structure of a membraneimpermeant antitumor sulfonamide complexed with isozyme II. J. Med. Chem., 48, 5721-5727.

73. Kim, Y.Y., Lee, E.J., Kim, Y.K., Kim, S.M., Park, J.Y., Myoung, H., Kim, M.J. (2010) Anti-cancer effects of celecoxib in head and neck carcinoma. Mol. Cells. 29, 185 194.

74. Gee, J.R., Burmeister, C.B., Havighurst, T.C., Kim, K. (2009) Cyclin-mediated G1 arrest by celecoxib differs in low-versus high-grade bladder cancer. Anticancer Res. 29, 3769-3775.

75. Tran-Thanh, D., Buttars, S., Wen, Y., Wilson, C., Done, S.J. (2010) Cyclooxygenase-2 inhibition for the prophylaxis and treatment of preinvasive breast cancer in a her-2/neu mouse model. Cancer Prev. Res. 3, 202-211.

76. Bhatt, R.S., Merchan, J., Parker, R., Wu, H.K., Zhang, L., Seery, V., Heymach, J.V., Atkins, M.B., McDermott, D., Sukhatme, V.P. (2010) A phase 2 pilot trial of low-dose, continuous infusion, or "metronomic" paclitaxel and oral celecoxib in patients with metastatic melanoma. Cancer, 116, 1751-1756.

77. Lipton, A., Campbell-Baird, C., Witters, L., Harvey, H., Ali, S. (2010) Phase II trial of gemcitabine, irinotecan, and celecoxib in patients with advanced pancreatic cancer. $\mathbf{J}$ Clin Gastroenterol. 44, 286-288.

78. Abbate, F., Casini, A., Owa, T., Scozzafava, A., Supuran, C.T. (2004) Carbonic anhydrase inhibitors: E7070, a sulfonamide anticancer agent, potently inhibits cytosolic isozymes I and II, and transmembrane, tumor-associated isozyme IX. Bioorg. Med. Chem. Lett., 14,217-223.

79. Abbate, F., Coetzee, A., Casini, A., Ciattini, S., Scozzafava, A., Supuran, C.T. (2004) Carbonic anhydrase inhibitors: X-ray crystallographic structure of the adduct of human isozyme II with the antipsychotic drug sulpiride. Bioorg. Med. Chem. Lett., 14, 337-341.

80. Supuran, C.T. (2018) Carbonic anhydrase inhibitors as emerging agents for the treatment and imaging of hypoxic tumors. Expert Opin. Investig. Drugs. 27, 963-970.

81. Neri, D., Supuran, C.T. (2011) Interfering with pH regulation in tumours as a therapeutic strategy. Nature Rev. Drug Discov., 10. 767-77

82. Schwartz, L., Supuran, C.T., Alfarouk, K.O. (2017) The Warburg effect and the hallmarks of cancer. Anticancer Agents Med. Chem., 17, 164-170.

83. Pacchiano, F., Carta, F., McDonald, P.C., et al. (2011) Ureido-substituted benzenesulfonamides potently inhibit carbonic anhydrase IX and show antimetastatic activity in a model of breast cancer metastasis. J. Med. Chem., 54, 1896-902

84.Lou, Y., McDonald, P.C., Oloumi, A., et al. (2011) Targeting tumor hypoxia: suppression of breast tumor growth and metastasis by novel carbonic anhydrase IX inhibitors. Cancer Res., 71, 3364-3376.

85. McDonald, P.C., Winum, J.Y., Supuran, C.T., Dedhar, S. (2012) Recent developments in targeting carbonic anhydrase IX for cancer therapeutics. Oncotarget. 3, 84-97

86. Bozdag M, Carta F, Ceruso M, et al. (2018) Discovery of 4-Hydroxy-3-(3-(phenylureido) benzenesulfonamides as SLC-0111 Analogues for the Treatment of Hypoxic Tumors Overexpressing Carbonic Anhydrase IX. J. Med. Chem., 61, 6328-6338

87. Pacchiano, F., Aggarwal, M., Avvaru, B.S., et al. (2010) Selective hydrophobic pocket binding observed within the carbonic anhydrase II active site accommodate different 4substituted-ureido-benzenesulfonamides and correlate to inhibitor potency. Chem. Commun. (Camb)., 46, 83718373.

88. Mboge, M.Y., Mahon, B.P., Lamas, N., et al. (2017) Structure activity study of carbonic anhydrase IX: Selective inhibition with ureido-substituted benzenesulfonamides. Eur. J. Med. Chem. 132, 184-191. 
89. Lau, J., Liu, Z., Lin, K.S., Pan, J., et al. (2015) Trimeric Radiofluorinated Sulfonamide Derivatives to Achieve In Vivo Selectivity for Carbonic Anhydrase IX-Targeted PET Imaging. J. Nucl. Med., 56, 1434-40.

90. Sneddon, D., Niemans, R., Bauwens, M., et al. (2016) Synthesis and in Vivo Biological Evaluation of (68)GaLabeled Carbonic Anhydrase IX Targeting Small Molecules for Positron Emission Tomography. J. Med. Chem., 59, 6431-43

91. Lau, J., Zhang, Z., Jenni, S., et al. (2016) PET Imaging of Carbonic Anhydrase IX Expression of HT-29 Tumor Xenograft Mice with (68)Ga-Labeled Benzenesulfonamides. Mol. Pharm., 13, 1137-46.

92. Supuran, C.T., Alterio, V., Di Fiore, A., D' Ambrosio, K., Carta, F., Monti, S.M., De Simone, G. (2018) Inhibition of carbonic anhydrase IX targets primary tumors, metastases, and cancer stem cells: Three for the price of one. Med. Res. Rev., 38, 1799-1836.

93. Park, K.D., Morieux, P., Salomé, C., Cotten, S.W., Reamtong, O., Eyers, C.,; Gaskell, S.J., Stables, J.P., Liu, R., Kohn, H. (2009) Lacosamide isothiocyanate-based agents: Novel agents to target and identify lacosamide receptors. J. Med. Chem., 52, 6897-6911
94. Temperini, C., Innocenti, A., Scozzafava, A., Parkkila, S., Supuran, C.T. (2010) The coumarin-binding site in carbonic anhydrase accommodates structurally diverse inhibitors: the antiepileptic lacosamide as an example. J. Med. Chem., 53, 850- 854.

95. Supuran, C.T., Scozzafava, A. (2004) Protein tyrosine kinase inhibitors as anticancer agents. Expert Opin. Ther. Pat., 14, 25-53

96. Parkkila, S., Innocenti, A., Kallio, H., Hilvo, M., Scozzafava, A., Supuran, C.T. (2009) The protein tyrosine kinase inhibitors imatinib and nilotinib strongly inhibit several mammalian $\square$-carbonic anhydrase isoforms. Bioorg. Med. Chem. Lett., 19, 4102-4106.

97. Winum, J.Y., Maresca, A., Carta, F., Scozzafava, A., Supuran, C.T. (2012) Polypharmacology of sulfonamides: pazopanib, a multitargeted receptor tyrosine kinase inhibitor in clinical use, potently inhibits several mammalian carbonic anhydrases. Chem. Commun. (Camb)., 48, 8177-8179 